\title{
Recent advances in neutralizing the IL-6 pathway in arthritis
}

This article was published in the following Dove Press journal:

Open Access Rheumatology: Research and Reviews

5 October 2009

Number of times this article has been viewed

\section{Charles J Malemud}

Division of Rheumatic Diseases, Case Western Reserve University, School of Medicine and University Hospitals Case Medical Center, Cleveland, Ohio, USA
Correspondence: Charles | Malemud Professor of Medicine and Anatomy, Department of Medicine, Division of Rheumatic Diseases, University Hospitals Case Medical Center, 206I Cornell Road, Cleveland, Ohio USA 44106-5076 $\mathrm{Tel}+\mathrm{I}(2 \mathrm{I} 6) 8447846$

Fax +I (216) 8442288

Email cjm4@cwru.edu
Abstract: Recent advances in understanding the mechanism(s) of how IL-6 trans-signaling regulates immune cell function and promotes inflammation in autoimmune arthritis are critically reviewed. Serum and/or synovial fluid (SF) IL-6 is markedly elevated in adult and juvenile rheumatoid arthritis (RA), psoriatic arthritis (PsA), ankylosing spondylitis (AS) and osteoarthritis (OA). IL-6, in concert with IL-17, determines the fate of CD4+ lymphocytes and therefore $\mathrm{TH}_{17}$ cell differentiation. IL-6 also plays a critical role in modulating B-lymphocyte activity. The recognition that IL-6 trans-signaling regulates inflammation resulted in the development of tocilizumab, a fully humanized monoclonal antibody that neutralizes the biological activity of the IL-6-receptor (IL-6R). Significant clinical benefit was demonstrated as well as reduced serum IL-6 levels with suppression of X-ray progression of disease in several clinical trials in which juvenile or adult RA patients were treated with tocilizumab monotherapy or tocilizumab plus methotrexate. However, levels of serum and/or SF IL-6 cytokine protein superfamily members, adiponectin, oncostatin M, pre-B-cell colony enhancing factor/visfatin and leukemia inhibitory factor are also elevated in RA. Additional studies will be required to determine if anti-IL-6 trans-signaling inhibition strategies with tocilizumab or recombinant soluble IL-6R reduce the level of these cytokines.

Keywords: interleukin-6, interleukin-6/interleukin-6 receptor/glycoprotein 130, JAK/STAT pathway, SAP/MAPK pathway, osteoarthritis, rheumatoid arthritis

\section{Introduction}

Interleukin-6 (IL-6) is a pleiotypic pro-inflammatory cytokine that has been shown to play a critical role in both the initiation and perpetuation of immunologic dysfunction and inflammatory responses in various forms of autoimmune arthritis as well as other inflammatory diseases of the gastrointestinal tract, heart and visual system. ${ }^{1}$ Several reviews of the published literature which focused on the relevant signal transduction pathways induced by IL- 6 that lead to changes in immunologic status and in the progression of inflammatory responses in these disorders all appeared in $2006 .{ }^{2-9}$ At that time, these summaries of the relevant in vitro and ex vivo studies mainly attempted to correlate IL-6 levels with disease activity in experimentally-induced animal models of human rheumatoid arthritis (RA). Additionally, a critical evaluation was undertaken regarding initial attempts to neutralize the IL-6 pathway in human arthritis. The results of these studies identified the IL-6/IL-6 receptor (IL-6R)/glycoprotein130(gp130) pathway as well as the existence of a soluble IL-6R (sIL-6R) form, later identified as the naturally occurring inhibitor of IL-6-mediated trans-signaling events, as potential targets for intervention in RA. In this regard, Nishimoto and Kishimoto ${ }^{5}$ suggested that the commercial 
development of IL-6R neutralizing monoclonal antibodies could be useful for suppressing IL-6-mediated trans-signaling in order to dampen T-lymphocyte and B-lymphocyte-mediated inflammatory responses in RA. Furthermore, Smolen and Maini $^{6}$ indicated that biological drugs of this kind were also likely to become invaluable for RA therapy when patients became refractory or non-responsive to first-line medical therapies employed in RA, including, non-steroidal antiinflammatory drugs and/or corticosteroids, disease-modifying anti-rheumatic drugs (DMARDs) such as methotrexate, hydroxchloroquine and sulfasalazine, biologic agents, such as one of several commercially available anti-tumor necrosis factor- $\alpha$ (anti-TNF- $\alpha$ ) monoclonal antibodies or TNF- $\alpha$ fusion proteins, and anti-B-lymphocyte depletion therapies exemplified by rituximab.

Since 2006 there have been significant advances in our recognition and understanding of how basic cellular and molecular mechanisms regulate and/or modulate the IL-6/IL-6R/gp130 pathway. In fact, the importance of IL-6-mediated trans-signaling in inflammatory diseases, such as juvenile idiopathic and adult RA, Crohn's disease and Castleman's disease resulted in the commercial development of tocilizumab, ${ }^{5,9-13}$ the first fully humanized anti-IL-6 monoclonal antibody used for the medical therapy of these disorders.

This review provides some important background information prior to, and including 2006, on the role of IL-6 transsignaling in inflammatory arthritis, but mainly focuses on the most recent and relevant advances in this area of basic and clinical research from 2007 to the present. A critical evaluation of the results of experimental and clinical studies will be provided and evidence presented as to why blockade of IL-6-mediated trans-signaling can be employed to suppress immune dysfunction and inflammation in arthritis. ${ }^{1,14-16}$ The results of the most recent studies have also helped define and identify additional novel targets where interventions originally focused on the IL-6/IL-6R/gp130 pathway may impact on the development and progression of arthritis and related rheumatic disorders. ${ }^{17-26}$

\section{IL-6/IL-6R/gp I30 pathway: mechanisms of action}

\section{T-helper cell differentiation}

The results of recent studies have elucidated the complex components of cell fate determination that lead to the further differentiation of T-helper cells (ie, $\mathrm{CD}^{+}$cells) and the formation of the Th17 T-lymphocyte subset lineage. ${ }^{27}$ Th17 cells had been previously shown to drive the progression of autoimmune arthritis via their capacity to synthesize IL-17A/B,
IL-21 and IL-22. ${ }^{28}$ Furthermore, in mice, differentiation of the Th17 cell lineage showed that transforming growth factor- $\beta$ (TGF- $\beta$ ), IL-6, IL-21 and IL-23, activation of the JAK/STAT pathway and retinoic acid-related orphan receptor- $\gamma$-at (ROR- $\gamma$-at) had to work in conjunction with each other to produce Th17 cells. Conversely, in mice, T-lymphocyte cytokines such as IL-2, the anti-inflammatory cytokine, IL-4, interferon- $\gamma$ (IFN- $\gamma$ ) and IL-27 were shown to inhibit Th17 cell differentiation. Adding to this level of complexity, IL-2 in concert with TGF- $\beta_{1}$ could also induce naïve $\mathrm{CD}^{+}$cells to become T-regulatory $\left(\mathrm{T}_{\text {reg }}\right)$ cells, the latter possessing the capacity to inhibit the progression of autoimmune arthritis. ${ }^{28}$

It is clear from the results of recent studies ${ }^{29-32}$ that several pro-inflammatory cytokines have been implicated in various downstream cellular pathways leading to Th17 cell fate determination. Additional evidence also indicated that the IL-6 pathway played a key role in regulating many IL-6-dependent cellular events that drive the progression of arthritis and other autoimmune disorders. ${ }^{33,34}$

The results of several studies have connected IL-6/IL-6R/ gp130 to Th17 cell development. ${ }^{28}$ Nishihara et al ${ }^{35}$ showed that although IL-6 promoted Th17 cell differentiation in mice, they could find no evidence for its role as a driver of $\mathrm{T}_{\text {reg }}$ cell development. Thus, mouse $\mathrm{CD}^{+}$cells with a mutated gp130 subunit could not activate Stat3. Furthermore, under these conditions, neither Th17 cells nor ROR- $\gamma$-at were produced. This result suggested that an intact IL-6/IL-6R/ gp130 complex was required for the development of Th17 cells. However, the number and percentage of $\mathrm{T}_{\text {reg }}$ cells was the same whether mutated gp130 or wild-type gp130 mice were analyzed indicating that an intact IL-6/IL-6R/gp130 complex was not absolutely essential for producing $\mathrm{T}_{\text {reg }}$ cells. Interestingly, engagement of the IL-6/IL-6R/gp130 complex in vitro suppressed $\mathrm{T}_{\text {reg }}$ cells development. Finally, Maitra et $\mathrm{al}^{36}$ recently showed that IL-1 receptor associated kinase (IRAK-1) modulated the differentiation of murine Th17 to produce $\mathrm{T}_{\text {reg }}$ cells. Following the stimulation of $\mathrm{CD}^{+}$cells derived from IRAK-1 null mice with T-cell receptor (TCR) agonists and TGF- $\beta$ these cells produced elevated levels of the transcription factor, nuclear factor of activated T-cells, cytoplasmic, calcineurin-dependent2 (NFATc2) as well as increased NFATc2/Smad3 interaction. This latter finding correlated with the increased expression of FoxP3, a marker for $\mathrm{T}_{\text {reg }}$ cell formation. By contrast, stimulation of $\mathrm{CD}^{+}$ cells from IRAK-1 null mice with TCR agonists, IL-6 and TGF- $\beta$ resulted in a reduction in Stat3 activation, which was accompanied by a reduction in IL-17 and ROR- $\gamma$-at 
production compared to wild-type $\mathrm{CD} 4^{+}$cells. Consequently, IRAK-1 deletion in mice apparently resulted in the reduced synthesis of IL-17 accompanied by a dampening of inflammatory responses.

\section{IL- 17: role in animal models of arthritis}

IL-6/IL-6R/gp130 also appears to plays a critical role in experimentally-induced autoimmune arthritis pathogenesis via its capacity to stimulate IL-17 production. Thus, Fujomoto et $\mathrm{al}^{37}$ showed that DBA/1 mice with collageninduced arthritis (CIA) had an increased frequency of Th17 cells, but not $\mathrm{TH}_{1}$ cells. Furthermore, blockade with an anti-IL-6R monoclonal antibody markedly suppressed the number of Th17 cells as well as the development of CIA, but treatment with anti-TNF receptor antibody failed to achieve this result. A more recent study by Lee et $\mathrm{al}^{38}$ then showed that IL-17 actually exacerbated CIA severity which was accompanied by the increased expression of Toll-Like Receptors (TLRs)-2, -4 and -9 as well as increased production of IL-6, IL-1 $\beta$, IL-17 and TNF- $\alpha$. Of note, IL-17 increased the expression of TLR-2, -4 and -9 in cultured synoviocytes from mice with CIA and this effect could be effectively neutralized by antibodies directed against IL-17, IL-1 $\beta$ or IL- 6 . These results also indicated that IL-17 worsened experimentallyinduced murine CIA by enhancing the expression of TLRs and further implicated IL-17 in arthritis progression via its capacity to augment IL-1 $\beta$ and IL- 6 production through TLR activation. Thus, enhanced TLR expression in response to IL-17 represents a novel feedback loop at the level of the synoviocyte wherein elevated IL-1 $\beta$ and IL-6 expression produced under these conditions promote TLR-induced inflammatory responses which continuously drive the progression and severity of experimental arthritis.

Ospelt et $\mathrm{al}^{39}$ showed that synovial tissue samples from RA patients had higher TLR-3 and -4 levels at an early stage of arthritis that were sustained at high levels in RA patients with longstanding disease. Furthermore, normal synovial fibroblasts expressed TLRs 1-6, but not TLRs 7-10. TLR-3 and TLR-4 were the most abundantly expressed TLRs in RA-synovial fibroblasts (RA-SF) and RA-SF responded to TLR ligands, Thus, TLR stimulation of RA-SF with the TLR-3 ligand poly (I-C) resulted in elevated levels of IL-6 and well as matrix metalloproteinase-3 (MMP-3; stromelysin-1) and MMP-13 (collagenase-3). As noted, skin fibroblast cultures were not altered by poly (I-C). ${ }^{39}$

Palmer et $\mathrm{al}^{40}$ determined that the Tec kinase, Bruton's tyrosine kinase $(\mathrm{Bmx})$ which has been previously implicated as a critical signaling kinase in regulating T-lymphocyte activation, natural killer cell activity, autoimmune responses and development of leukemia ${ }^{41}$ was the regulator of TLR-4induced IL-6 synthesis in macrophages where increased IL-6

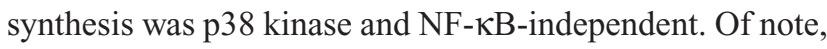
LPS also stimulated Bmx in synoviocytes isolated from RA synovial tissue which resulted in up-regulation of IL-6 and vascular endothelial growth factor (VEGF) gene expression. ${ }^{42}$ Hashizume et $\mathrm{al}^{43}$ showed that RANK ligand (RANKL), a promoter of osteoclast differentiation was induced by IL-6 and sIL-6R, but not by IL-6 alone, in RA fibroblast-like synoviocytes (RA-FLS). Neither IL-17 nor TNF- $\alpha$ alone induced the expression of RANKL. However, TNF- $\alpha$, IL-17, IL-1 $\beta$ stimulated the proliferation of RA-FLS and induced IL-6 gene expression as well as inducing activation of Stat3 and ERK 1/2.

The results of these recent studies ${ }^{38-40}$ suggested two novel perspectives for the role of the IL-6/IL6R/gp130 pathway in autoimmune arthritis. One avenue to pursue further is the apparent strong link between enhanced TLR expression as a consequence of the development of autoimmune arthritis and the elevated production of IL- 6 accompanied by MMP gene upregulation. Another is the relationship between IL-6 and sIL6R in driving the activation of the JAK/STAT pathway, which may be amenable to the action of small molecule JAK inhibitors. ${ }^{1}$

\section{Effect on IL-6 on SAP/MAPK signaling}

The now classical study from the Firestein laboratory by Inoue et $\mathrm{al}^{44}$ convincingly linked pro-inflammatory cytokinemediated activation of stress-activated/mitogen-activated protein kinases (SAP/MAPKs) and, p38 kinase in particular, to several cellular events generally associated with arthritis pathophysiology. In that regard, IL-1 $\beta$-induced IL-8, IL-6 and MMP-3 production by RA-FLS was significantly suppressed by transfecting the cells with dominant-negative mutations of mitogen-kinase-kinase-3/6 (MKK-3)/MKK-6, both of which are generally required for the full activation of p38 kinase. ${ }^{45}$ Of importance, activation of p38 kinase as well as the activation of two other SAP/MAPK members, namely, ERK 1/2 and JNK were also associated with the activation of the transcription factor, NF- $\kappa B .{ }^{46}$ In a follow-up study, Inoue et $\mathrm{al}^{47}$ showed that TNF- $\alpha$ activated $\mathrm{p} 38$ kinase by wild-type synovial fibroblasts ex vivo, but not by synovial fibroblasts isolated from $\mathrm{MKK}^{-/}$transgenic mice. Additionally, IL-1 $\beta$ and IL-6 levels were markedly lower in the $\mathrm{MKK}^{-/}$transgenic mice. Importantly, this study showed that TNF- $\alpha$-induced IL- 6 production was NF- $\kappa B-$ dependent. These results of these in vitro were extended by 
employing 2 animal models of arthritis; the passive transfer of arthritic $\mathrm{K} / \mathrm{BxN}$ serum model and rodent arthritis produced by administration of lipopolysaccharide (LPS). The results of the ex vivo studies were sustained in the $\mathrm{K} / \mathrm{BxN}$ arthritic $\mathrm{MKK}^{-/-}$transgenic mice, but not in $\mathrm{MKK}^{-/-}$transgenic mice administered LPS, wherein IL-6 production was similar in $\mathrm{MKK}^{-/-}$transgenic mice as compared to wildtype mice. More recently, Yoshizawa et $\mathrm{al}^{48}$ from the same research group compared the development of inflammatory arthritis by wild-type mice with the development of arthritis in $\mathrm{MKK}^{-/-}$and $\mathrm{MKK}^{-/-}$transgenic mice administered serum from $\mathrm{K} / \mathrm{BxN}$ mice. Arthritis scores were significantly lower in $\mathrm{MKK}^{-/-}$mice compared to their wild-type counterparts as was IL-6 and MMP-3 levels measured in articular tissues. Interestingly, activated p38 levels were only modestly decreased in arthritic MKK6 $6^{-1-}$ mice, but activated p38 levels were significantly higher than were found in the arthritic $\mathrm{MKK}^{-/-}$mice. Of note, the activity of the further upstream kinase, MK2 was low in both $\mathrm{MKK}^{-/-}$and $\mathrm{MKK}^{-/-}$mice. These results indicated that a deficiency in MKK6 resulted in suppression of murine arthritis induced by passive transfer of arthritic $\mathrm{K} / \mathrm{BxN}$ serum. Further, these results showed that the reduced severity of arthritis in $\mathrm{MKK} 6^{-1-}$ mice was accompanied by lowered levels of IL-6 and MMP-3 suggesting that the IL-6/MMP-3 relationship established previously in vitro with human synoviocytes ${ }^{38}$ appeared to be sustained in whole animal studies as well.

\section{Role of IL- 6 in NF- $\kappa B$ activation}

Previous studies linked IL-1 $\beta$-mediated activation of $\mathrm{p} 38$, ERK $1 / 2$ and JNK to the activation of NF- $\kappa B .{ }^{46,49}$ In this regard, epigallocatechin-3-gallate (EGCG), a strong inhibitor of JNK activation in cultured human chondrocytes, also inhibited NF- $\kappa$ B activation. ${ }^{50}$ Now, Ahmed et $\mathrm{al}^{51}$ have shown that treatment of arthritic rats with EGCG also resulted in the suppression of IL-6, membrane-bound gp130 protein and MMP-2 (ie, $72 \mathrm{kDa}$ gelatinase) levels that were measured in joint homogenates. The reduction in the levels of these 3 biomarkers was accompanied by a reduction in the severity of arthritis. By contrast, the level of soluble pg130 (spg130) was increased after treatment with EGCG. However, the cellular mechanism accounting for the capacity of EGCG to stimulate spg130 in vivo and its role in suppressing IL-6 and MMP-2 needs to be further clarified.

Bradykinin, a potent mediator of inflammation in RA also induced IL-6 production by human RA-SF in vitro. Of note, the bradykinin effect on IL-6 synthesis by RA-SF could be attenuated by treatment with small molecule inhibitors of phospholipase $\mathrm{C}, \mathrm{PKC} \delta, \mathrm{NF}-\kappa \mathrm{B}, \mathrm{I} \kappa \mathrm{B}$ or an $\mathrm{NF}-\kappa \mathrm{B}$ inhibitor peptide. $^{52}$

[(1R)-3-methyl-1[[(2S)-1-oxo-3-phenyl-2-pyrazinylcarbonyl) amino] propyl] amino] butyl] boronic acid (ie, bortezomib), an inhibitor of NF- $\mathrm{KB}$ activation and proteasome activity ${ }^{53}$ was recently shown to significantly attenuate CIA in DBA/ 1 mice. ${ }^{54}$ The reduced severity of arthritis produced by bortezomib, as measured by a decrease in the level of joint destruction, was accompanied by a decrement in TNF- $\alpha$, IL-1 $\beta$, IL-6, MMP-3, COX-2 and iNOS. No adverse effects of bortezomib on blood cells, kidney or liver were detected.

\section{Potential important role of IL-6 in B-lymphocyte activation}

Activated RA synovial tissue is principally defined by its hyperplasia. Under these conditions, the normally quiescent synovial fibroblast becomes an activated cell through the capacity of pro-inflammatory cytokines to induce a robust synovial fibroblast proliferative response accompanied by apoptosis resistance. ${ }^{55}$ Additionally the synovial membrane becomes extensively infiltrated with mast cells, neutrophils, macrophages and T- and B-lymphocytes, the latter which spatially re-organize the structure of synovial tissue to produce germinal centers. ${ }^{28,56} \mathrm{~A}$ key step in the formation of germinal centers is that B-lymphocytes 'revise' the structure of their surface receptors which is stimulated by the up-regulation of recombinant activating genes-1, -2 (RAG-1, -2). Thus, RAG-1, -2 reinitiate immunoglobulin gene recombination and modify B-lymphocyte antigen recognition and responsiveness. ${ }^{57}$ In this regard, secondary VDJ rearrangements and abundant RAG protein levels were detected in RA synovial tissue. It is also noteworthy that Rochas et $\mathrm{al}^{58}$ showed that RA-FLS, but not OA- FLS, induced B-lymphocytes to re-express RAG mRNA and RAG proteins in vitro. Further, transmembrane B-cell activating factor (BAFF), ${ }^{59,60}$ a member of the TNF- $\alpha$ protein superfamily, must be available to provide the initial signal for RAG protein expression. Most importantly, blockade of IL-6R suppressed RAG gene expression by B-lymphocytes induced by RA FLS. ${ }^{58}$ This result suggested that at least two signals, one involving BAFF and the other requiring activation of the IL-6/IL-6R/gp130 pathway were essential for RA synovial tissue to induce RAG protein expression by B-lymphocytes. The role of BAFF in $\mathrm{CD}^{+} \mathrm{B}-1$ lymphocyte activation was also studied by $\mathrm{Ng}$ et $\mathrm{al}^{61}$ in BAFF null and BAFF receptor (BAFF-R) null mice which have a normal complement of B-1 cells. Treatment of B-1 cells with BAFF increased NF- $\kappa B$ processing and CD21/CD23 expression, the latter being 
a strong indicator of B-lymphocyte maturation. Furthermore, TLR engagement of B-1 cells augmented BAFF-R expression and stimulation of BAFF-R resulted in elevated levels of IL-6 and the anti-inflammatory cytokine, IL-10. Ultimately, it may be the relative ratio of IL- 6 to IL-10 in response to BAFF-R activation that augments or suppresses inflammation in these mice.

BAFF antagonists (eg, A-623 and BR3-Fc) as well as inhibitors of 'a proliferating-inducing ligand' (APRIL), a molecule homologous to BAFF, have been studied in arthritis animal models $\mathrm{s}^{62,63}$ as well as in some clinical trials ${ }^{64}$ the latter being considered for possible future use in the treatment of autoimmune arthritis. Thus, BAFF/APRIL antagonists are likely to be involved in the elimination of autoreactive B-lymphocytes ${ }^{60}$ and inhibition of the BAFF/APRIL pathway may also be useful to probe the relationship between BAFF/APRIL-stimulated B-lymphocyte survival and BAFF/ APRIL activation of the IL-6/IL-6R/gp130 pathway.

\section{IL-6 protein family members}

Adiponectin (APN), oncostatin M (OSM) and pre-B-cell colony enhancing factor (PBEF), also known as visfatin, are three members of the IL- 6 protein superfamily which were recently proposed to play significant roles in autoimmune arthritis.

\section{APN}

Among the 3 IL-6-like proteins, APN, OSM and PBEF, only APN was shown to be highly selective in its capacity to induce IL-6 and MMP-1 synthesis in human synovial fibroblasts in vitro. ${ }^{65}$ Induction of IL-6 and MMP-1 required p38 kinase activity. Importantly, the effect of APN could be ablated by anti-TNF receptor blockade. Additionally, Haugen and Drevon ${ }^{66}$ used the macrophage cell line U937 to show that physiologic concentrations of globular APN induced $\mathrm{NF}-\kappa \mathrm{B}$ activation and further, that APN was more potent in this regard, than leptin, resistin or IL-6. Interestingly, NF- $\kappa B$ activation by globular APN was not affected by neutralizing antibodies reactive with TLR 4 or TNF receptors 1 and 2, but NF- $\mathrm{KB}$ activation was suppressed by inhibitors of $\mathrm{p} 38$ kinase, PI3K and PKC activity, once again indicating that a considerable level 'cross-talk' occurs between three signaling pathways, all of which appear to be required for the effect of globular APN on NF- $\kappa$ B activation. Tang et $\mathrm{al}^{67}$ using RA- FLS, instead of a macrophage cell line, confirmed that APN activated p38 kinase, but also showed that 5'AMP-activated protein kinase was phosphorylated in these cells after treatment with APN. However, in this study, ${ }^{67}$
APN stimulated IL-6 synthesis which was dependent on the activation of NF- $\kappa \mathrm{B}$. Thus, in RA-FLS, APN activated I $\mathrm{B}$ kinase- $\alpha / \beta$ (ie, APN stimulated the phosphorylation of I $\kappa$ B- $\alpha$ and also I $\kappa$ B- $\beta$ degradation), phosphorylation of the p65 subunit of the NF- $\kappa B$ complex at $\operatorname{Ser}^{265}$ as well as nuclear translocation of the $\mathrm{p} 65$ and $\mathrm{p} 50 \mathrm{NF}-\kappa \mathrm{B}$ subunits. APN-stimulated IL-6 and NF- $\kappa B$ activation could be inhibited by the $\mathrm{p} 38$ kinase SMI, SB203580 or by an APN receptor (ie, AdipoR1) siRNA which indicated that APN induced IL-6 synthesis in RA-FLS by interacting with AdipoR1 with resultant downstream p38 kinase activation. Lee et $\mathrm{al}^{68}$ also studied the role of APN in inducing IL-6 in human RA-FLS but also extended studies of APN in the aforementioned in vitro studies ${ }^{65-67}$ when they asked if APN was involved in altering the severity of CIA in DBA/1 mice? APN was shown to suppress arthritis severity in DBA/1 mice. The effect of APN on reducing the severity of CIA was accompanied by a significant decrease in TNF- $\alpha$, IL-1 $\beta$ and MMP-3 gene expression, but not IL-6 gene expression. The same results were obtained when RA-FLS were incubated with APN. APN reduced TNF- $\alpha$, IL-1 $\beta$ and MMP-3 gene expression, but increased IL-6 expression in IL-1 $\beta$-stimulated cells. Taken together, these results ${ }^{65-68}$ suggested that APN could be considered a potential anti-arthritis cytokine because it could attenuate the severity of CIA. However, the role of APN as a modifier of IL- 6 production in RA and how regulating IL-6 alters arthritis severity in CIA requires additional study.

\section{OSM}

A recent review of the literature has recognized the important role that OSM plays in the pathogenesis and progression of RA and OA. ${ }^{69}$ However, the specific functions of OSM occurring during an inflammatory challenge remains uncertain. In order to provide additional insight into the putative role played by OSM in inflammation, Hams et al $^{70}$ employed IL-6-deficient, OSM receptor- $\beta$ (OSM-R $\beta$ )-deficient knockout (KO) mice and their wildtype counterparts to determine the role of OSM in modulating cytokine-mediated recruitment of leukocytes in an acute peritoneal model of inflammation. Interestingly, OSM-R $\beta-K O$ mice showed enhanced monocyte trafficking compared to IL-6-deficient or wild-type mice. However, in contrast to IL-6 null mice, OSM-R $\beta$ KO mice showed no differences in the level of neutrophil or lymphocyte migration into the inflamed peritoneum. A follow-up analysis using human peritoneal mesothelial cells then identified OSM as a potentially important regulator of the CCL5 chemokine gene expression. In that regard, OSM inhibited IL-1 $\beta$-mediated 
$\mathrm{NF}-\kappa \mathrm{B}$ activation and CCL5 gene expression. These results indicated that IL-6 and OSM can act as separately-active pro-inflammatory cytokines to influence the level and profile of inflammatory cell migration and chemokine production. Furthermore, these results suggested that neutralizing IL-6/ IL-6R/gp130 pathway activation may not have significant effects on OSM/OSMR $\beta$-mediated events.

\section{PBEF}

PBEF, also known as visfatin, is a highly evolutionarily conserved $52 \mathrm{kDa}$ protein that has been implicated in the regulation of cellular energy and in modulating innate immunity. However, its role in inflammation appears to be particularly related to its capacity to induce TNF- $\alpha$, IL- $1 \beta$ and IL-6 gene expression. ${ }^{71}$ In that regard, Nowell et $\mathrm{al}^{72}$ used cDNAs produced from human RA-FLS to determine which if any of several pro-inflammatory cytokines were altered by treatment with PBEF. They also employed wild-type and IL-6-deficient mice with AIA to see if PBEF altered the severity of arthritis. IL-6 trans-signaling was shown to regulate PBEF expression that was dependent on the activation of Stat3. OSM was also shown to upregulate PBEF expression which did not occur with leukemia inhibitory factor (LIF) or IL-11-treated cells. In AIA, synovial tissue expression of PBEF was increased 4-fold. The 4-fold increase in PBEF expression was not seen in IL-6 KO mice with AIA where inflammatory infiltrates were also reduced as was the presence of activated Stat3. An analysis of human synovial tissue from this study showed that PBEF was significantly elevated in RA compared to OA synovial tissue. In RA synovium, PBEF was immunolocalized to the apical surface of synovial membrane cells, endothelial cells, adipocytes and lymphoid aggregates. A more recent study also employing RA-FLS showed that PBEF activated NF- $\kappa$ B and activator of protein-1 (AP-1) along with IL-6, IL-8, MMP-1 and MMP-3. ${ }^{73}$ This result was confirmed by the fact that knockdown of PBEF gene expression in RA-FLS significantly inhibited basal and TLR ligand-induced synthesis of IL-6, IL-8, MMP-1 and MMP-3.

\section{Serum amyloid $A$}

Amyloid A is an acute phase reactant protein produced principally in the liver. Serum amyloid A (SAA) is often employed as one of several surrogate markers of inflammation in autoimmune arthritis. ${ }^{74}$ Koga et $\mathrm{al}^{75}$ showed that recombinant SAA stimulated IL-6 production by RA-FLS which also required activation of p38 kinase, the p46/p52 isoforms of JNK and NF- $\mathrm{KB}$.

\section{What additional mechanisms have been revealed by IL-6 blockade in recently conducted experimental studies in animal models of RA? Tocilizumab: amelioration of CIA in non-human primates}

Recent studies have been conducted in non-human primate models of CIA where relevant cellular immune mechanisms that are disrupted by blockade of the IL-6/IL6R/gp130 pathway with tocilizumab can be further explored. Uchiyama et $\mathrm{al}^{76}$ showed that the development of CIA in female cynomolgus monkeys was suppressed after administration of tocilizumab 4 weeks after the onset of arthritis. The reduction in arthritis severity was accompanied by a significant decrease in joint swelling as well as in the level of neutrophils infiltrating the arthritic joints. Of note, anti-tocilizumab antibodies were not detected during the treatment period. Kato et $\mathrm{al}^{77}$ focused on the extent to which tocilizumab could alter RANKL and osteoclast differentiation in primate CIA. Tocilizumab suppressed osteoclast development in vivo. In situ, a monolayer of immature osteoclast/stromal was observed in the tocilizumab-treated monkeys with CIA, whereas in non-tocilizumab-treated animals the cells were multi-layered and resembled differentiated osteoclasts. The suppression of osteoclast differentiation by tocilizumab in vivo was accompanied by a decrement in RANKL which was produced at high levels in the control group as well as a reduction in the amount of interstitial fluid and reticulum fibers in hemopoietic bone marrow. These data indicated that blockade of IL-6/IL-6R by tocilizumab in primate CIA suppressed subchondral bone resorption and the disruption of bone marrow structure both of which are hallmarks of bone destruction in chronic human RA.

\section{Potential novel mechanisms revealed for the role of IL-6 in experimentally induced rodent arthritis}

Either the antibody specific for glucose-6-phosphate isomerase (G6PI) found in the serum of $\mathrm{K} / \mathrm{BxN}$ arthritic mice, or G6PI itself, can be successfully employed to induce acute arthritis in DBA/1 mice where chronic joint deformation is self-limiting. ${ }^{78}$ However, up until recently, the role of IL-6 in G6PI-induced arthritis was unknown. Now, Matsumoto et $\mathrm{al}^{79}$ has shown that the levels of TNF- $\alpha$ and IFN- $\gamma$ were elevated compared to IL-2 and IL-6 in splenocytes derived from mice with G6PI-induced arthritis. Interestingly, a single injection of 
combined therapy with anti-TNF- $\alpha$ and anti-IL- 6 antibodies together with 2 injections of anti-cytotoxic T-lymphocyte antigen-4-Ig (CTLA-4-Ig) reduced the severity of arthritis, whereas injections of anti-IFN- $\gamma$ and anti-IL-12 did not. In fact, injections with the latter antibody combination appeared to exacerbate arthritis. Of note, the therapeutic efficacy of the anti-TNF/anti-IL-6/anti-CTLA-4-Ig regimen correlated with reduced levels of anti-G6PI antibodies. Although no mice with G6PI-induced arthritis was treated with anti-IL-6 antibodies alone, the results of the combined anti-TNF- $\alpha$ /anti-IL-6/anti-CTLA-4-Ig treatment regimen suggested that, at the very least, more than one receptormediated signaling pathway was needed to neutralize and suppress G6PI-induced murine arthritis. By contrast, the IFN- $\gamma$ pathway appeared to be relegated to a position of regulator of G6PI-induced arthritis progression rather than G6PI-induction. To further address the role of IFN- $\gamma$, IL-6R as well as IL-17 in G6PI-induced arthritis, Iwanami et al ${ }^{80}$ treated DBA/1 mice with G6PI-induced arthritis separately with specific monoclonal antibodies reactive against each cytokine. Administration of anti-IL-6 (ie, monoclonal antibody MR16-1) alone on day zero or day 3 ameliorated the induction of arthritis whereas administration of MR16-1 on day 8, suppressed existing arthritis. A similar result was obtained with anti-IL-17 administration on day 7, but not on day 14. Administration of anti-IFN- $\gamma$ worsened arthritis. MR16-1 therapy alone inhibited Th17 differentiation but did not alter Th1, Th2 or $\mathrm{T}_{\text {reg }}$ cell levels. MR16-1 also suppressed $\mathrm{CD}^{+}$cell proliferation. These results further supported the view that the early effector phase of G6PI-induced murine arthritis development was dependent on IL-6R and IL-17.

The role of IL- 6 and Th17 responses as well as their effects on modulating chemokine and chemokine receptor levels was also studied in CIA mice using a novel water-soluble immunosuppressive agent, 1-(12 $\beta$-dihydroartemisinoxy)2-hydroxy-3-tert-butylaminopropane (SM905). ${ }^{81}$ SM905 delivered orally before or after the onset of CIA in DBA/1 mice suppressed the incidence and severity of arthritis which was accompanied by a reduction in the level of inflammation, as well as lower pro-inflammatory cytokine, chemokine and chemokine receptor levels in draining lymph nodes. In support of this latter finding, anti-IL6 R blockade with tocilizumab was recently shown to reduce the synthesis of the monocyte chemotactic protein-1, (MCP-1/CCL2) and IL-8/CXCL8 chemokines by the macrophage-like U937 cell line that were treated with IL-6 or IL-6 and sIL-6R. ${ }^{82}$ Furthermore, the adhesion of U937 to human umbilical vessel endothelial cells (HUVEC) was increased when HUVEC were pre-treated with IL-6 and sIL-6R. The increased adhesion of U937A to HUVEC adhesion could be prevented by antiintercellular adhesion molecule-1/CD54 and tocilizumab, but not by anti-vascular cell adhesion molecule-1/CD106 or anti-E-selectin.

Of note, cell culture studies conducted ex vivo from mice with CIA with or without SM905 showed that type IIcollagen-induced T-lymphocyte proliferation and the production of IL-17A and ROR- $\gamma$-at were significantly suppressed in mice with CIA treated with SM905, as was the synthesis of IL- $6 .{ }^{81}$ The results of this study supported the view that amelioration of CIA could be accomplished only by reducing the levels of both Th17 and IL-6.

Antigen-induced arthritis (AIA) in rodents is dependent on the activation of $\mathrm{CD}^{+} \mathrm{T}-1 y m p h o c y t e s$, but not on the activity of $\mathrm{CD}^{+}$lymphocytes or B-lymphocytes. Wong et al ${ }^{83}$ showed that IL- 6 null mice had less severe arthritis and had fewer numbers of osteoclasts at the sites of bone erosions observed in wild-type mice. By contrast, OSM-R null mice had significant arthritis which was similar to that seen in TNF- $\alpha$ and IL-11 null mice. As expected, TNF- $\alpha$ blockade suppressed AIA in wild-type mice. T-lymphocytes from IL-6 null mice produced less IL-17 and RANKL relative to osteoprotegerin and generated fewer osteoclasts than that seen in either wild-type or TNF- $\alpha$-deficient mice. The results from this analysis again emphasized the close association between IL-6-induced inflammatory responses in mice, IL-17 levels and the degree of osteoclastogenesis that contributes to murine arthritis pathophysiology.

High mobility group box chromosomal protein1 (HMGB1), also named amphoterin, is a $30 \mathrm{kDa}$ nuclear protein which is loosely bound to DNA and stabilizes nucleosome formation while also regulating transcription. ${ }^{84} \mathrm{HMBG} 1$ also interacts with TLR-2 or TLR-4 which may account for its role as a proinflammatory mediator. ${ }^{85}$ In some cases, it has been shown that HMGB1 behaves as if it were a pro-inflammatory cytokine. In that regard, HMBG1 has been proposed to contribute to the pathogenesis of autoimmune arthritis by facilitating not only Mac-1/CD11b/CD18-dependent neutrophil recruitment and migration of neutrophils to sites of inflammation ${ }^{86}$ but also by being released from immune cells in response to TNF- $\alpha .{ }^{87}$ To further explore the relationship between HMGB1, TNF- $\alpha$ and their potential effects on IL-6-mediated synovitis, Pullerits et a ${ }^{87}$ compared the incidence and severity of arthritis in TNF- $\alpha \mathrm{KO}$ and TNF- $\alpha^{+/+}$mice that received an intra-articular injection of recombinant HMGB1 (rhHMGB1). Administration of rhHMGB1 resulted in only $32 \%$ to $39 \%$ of the TNF- $\alpha \mathrm{KO}$ mice developing arthritis. 
Moreover, there were no differences in either arthritis incidence or severity induced by HMBG1 between mice with normal TNF- $\alpha$ and TNF- $\alpha$-deficient mice. Further, no differences could be detected in the production of IL- 6 by splenocytes isolated from either mouse group. However, after stimulation with rhHMGB1 ex vivo, the splenocytes from TNF- $\alpha^{+/+}$mice released significantly more IL- 6 than the splenocytes from TNF- $\alpha$ KO mice. These results suggested that HMBG1 could induce arthritis independent of TNF- $\alpha$ and that IL-6 released from splenocytes in response to rhHMBG1 in vitro may provide a novel pathway for exploring the role of HMBG1 in the promotion of inflammation associated with progression of arthritis. However, additional in vivo data using well-validated murine arthritis models must be studied to validate this putative HMBG1/IL-6 relationship.

Several additional mechanisms involving IL-6/IL-6R may be amenable to intervention in experimentally-induced arthritis. For example, Milici et al ${ }^{88}$ showed that CP-690550, a Jak3 SMI, and a key enzyme involved in IL-6, IL-2, IL-7, IL-15 and IL-21-mediated signaling ${ }^{1}$ decreased the severity of CIA and AIA by suppressing the recruitment of inflammatory cells into the synovial joint, thus limiting damage to cartilage and bone. In another study, mice were bred that were deficient in subunit gp130 function by virtue of a point mutation in $\mathrm{Tyr}^{759}$ (ie, gp130F759 mice). Tsuji et al ${ }^{89}$ analyzed the development of CIA in gp130F759 mice with a DBA/1J background (ie, D/J.gp130F759). The arthritis in D/J.gp130F759 mice was more severe with greater bone destruction compared to control mice with normal gp130 function. Thus, following collagen II immunization, splenomegaly, serum rheumatoid factor and anti-DNA antibody titers were elevated In D/J.gp130F759 mice. Of note, elevated levels of IL-12 and platelet-derived growth factor were also detected prior to collagen immunization, but increased levels of INF- $\gamma$, IL-17, TNF- $\alpha$, IL-9 and macrophage inflammatory protein- $1 \beta$ were found only after collagen immunization. These results indicated that the gp130 F759 mutation was the cause of autoimmune arthritis in these mice, but that the development of arthritis was also influenced by genetic background. Since arthritis severity in D/J.gp130F759 mice could be partially ameliorated by methotrexate, this novel animal arthritis model could be useful for determining additional cellular downstream events that are altered by the gp130F759 mutation. For example, the gp130F759 mutation has already been shown to require IL-7 and Stat3 activation for driving the development of arthritis in these mice..$^{90}$ Thus, conditional KO of Stat 3 in non-lymphoid cells confirmed that the elevated production of IL-7 and expansion of $\mathrm{CD} 4{ }^{+}$cells was dependent on the activation of Stat 3 by IL- 6 family cytokines. Importantly, anti-IL-7 antibody suppressed arthritis severity in these gp130 mutant mice.

A group of Danish blood donors with high anti-IL-6 antibody titers do not appear to exhibit any clinical signs of arthritis. Galle et $\mathrm{a}^{91}$ made immunogenic IL-6 analogues to produce anti-IL-6 antibody (aAB-IL-6) titers in mice at levels comparable to those measured levels of anti-IL-6-antibody in these human blood donors. The aAB-IL-6 'vaccine' was used to treat mice with CIA and experimental allergic encephalitis (EAE). Mice vaccinated with aAB-IL-6 were protected against the development of CIA and EAE, although aAB-IL-6-vaccinated mice showed increased levels of TNF- $\alpha$ after a challenge with LPS. Thus, it remains to be determined whether a regimen using aAB-IL-6 could potentially serve as a prophylactic immunotherapeutic vaccine with the goal of preventing the development of familial inflammatory disorders that are characterized by elevated IL-6 levels.

\section{Clinical investigations and clinical trials IL-6 profiling in human arthritis}

Over the preceding 4 years several human studies have focused on correlating IL-6 levels in serum, plasma or SF with clinical measurements of disease activity, markers of inflammation as well as development of, and radiographic progression of RA. Perry et $\mathrm{al}^{92}$ were the first to show that the concentration of IL- 6 in paired plasma and SF from RA patients that were sequentially measured over a 6-hour period varied independently with one another. Furthermore, the plasma IL-6 levels fell precipitously during the measuring period whereas the IL-6 levels in SF remained virtually constant. This result challenged the view that plasma IL-6 was a surrogate measurement for synovial tissue IL-6 production. Additional studies from this group examined the diurnal variations in TNF- $\alpha$, IL- 6 and other hormones. Thus, Perry et $\mathrm{l}^{93}$ showed that the mean IL-6 and cortisol levels showed significant overnight variation in RA patients who had not received glucocorticoid therapy, with IL-6 levels significantly rising overnight. However, there were no variations in either the levels of TNF- $\alpha$, or that of IL-1 $\beta$, IL-4, IL-10 and IL-13 during the same time period. Thus, the overnight rise in plasma IL-6 may be a useful biomarker for taking into account circadian variations in RA symptoms as well as for measuring responsiveness of RA patients to various medical therapies. In fact, Matsumoto et $\mathrm{al}^{94}$ found a positive, significant correlation between the index of inflammatory cell 
infiltrate in synovial tissues and the SF IL-6 concentration. There was also a significant positive relationship between SF IL-6 levels and plasma CRP as well as plasma CRP and the inflammatory cell infiltrate index.

Karlson et $\mathrm{al}^{95}$ reported that the median plasma IL-6 and sTNFRII levels were significantly higher in subjects from the Nurse's Health Study (NHS) cohort prior to the onset of RA symptoms, but who eventually went on to develop RA, compared with subjects who did not develop RA in the NHS cohort. Interestingly, this relationship did not hold in subjects from the Women's Health Study (WHS) cohort. However, pooled data from NHS and WHS cohorts did show a significant association of sTNFRII with those subjects that eventually went on to develop RA (RR, 2.0 ; 95\% confidence interval $[\mathrm{CI}], 1.1$ to $3.6 ; P$ for trend $=0.004$ ), but only a modest association of IL-6 in the pre-clinical RA group $(\mathrm{RR}, 1.4 ; 95 \% \mathrm{CI}, 0.8$ to $2.5 ; P$ for trend $=0.06)$ who later developed RA.

Studies with a similar theme were performed on subjects with juvenile idiopathic arthritis (JIA), ${ }^{96} \mathrm{PsA}^{97}$ and on patients with aggressive periodontitis coupled to chronic arthritis. ${ }^{98}$ Although significantly higher levels of IL-6 were found in paired plasma and SF samples from JIA patients, along with IL-15 and several additional chemokines, when compared to normal subjects or Type I diabetes subjects, ${ }^{89}$ levels of IL-8, macrophage inhibitory factor, CCL2, CCL3, CC11, CXCL9 and CXCL10 appeared to be more valuable than IL-6 for assessing the future course of treatment as these biomarkers correlated most closely to when JIA became activated. In PsA patients, serum IL-6 levels were significantly higher in subjects with joint disease and measurable inflammation compared to subjects without joint inflammation. Serum IL-6 levels correlated most significantly with the actual inflamed joint count, erythrocyte sedimentation rate (ESR), C-reactive protein (CRP) levels, but not with soluble IL-2R $\alpha$ levels. In comparison with a control group, serum sTNFRII levels were most significantly correlated with disease activity in patients with generalized aggressive periodontitis or JIA. ${ }^{98}$ By contrast, a negative correlation was obtained when IL-6 gene expression and plasma IL-6 levels were compared between JIA and a control group. By contrast, a positive significant correlation was found in TNFRI expression and sTNFRI plasma levels when patients with localized aggressive periodontitis and RA were compared to the control group.

A critical analysis of these results indicated, that for the most part, plasma and/or SF IL-6 levels may be useful biomarkers to monitor disease activity in several types of inflammatory arthritic conditions, including adult RA, PsA or
JIA. However, in RA associated with aggressive periodontitis, monitoring the plasma levels of TNFRI, TNFRII or sTNFRI may be more valuable.

\section{Do changes occur in serum IL-6 levels after treatment of RA patients with biological agents? Infliximab}

Amital et $\mathrm{al}^{99}$ studied serial serum samples from 11 patients with refractory RA, 3 with PsA and 1 patient with undifferentiated spondyloarthropathy, all of whom were treated with infliximab after failing to attain sustained clinical remission with conventional therapies or DMARDs. Seventy-two percent (8/11) of the RA patients had elevated serum levels of TNF- $\alpha$ at least once during the study period. Only 1 RA patient was clinically unresponsive to infliximab, whereas 2/11 RA patients clinically responded to infliximab but never exhibited elevated TNF- $\alpha$ levels either before or after infliximab therapy. One of the RA patients who clinically responded to infliximab continued to manifest high serum TNF- $\alpha$, as well as IL-6 and sIL-2R levels, despite general clinical improvement. Of note, serum IL-1 $\beta$ and IL-10 levels continued to remain in the normal range in all of the RA patients. Interestingly, $100 \%$ of the PsA patients clinically responded to infliximab despite having no reduction in their high serum level of TNF- $\alpha$. The 15-year-old patient with undifferentiated spondyloarthopathy responded clinically to infliximab, but also continued to have high serum TNF- $\alpha$. In another study, ${ }^{100}$ cytokines and cell types were determined by immunohistochemical analysis of synovial tissue to assess the response of 32 RA patients who had pre-treatment synovial biopsies followed by post-treatment synovial biopsies after 16 weeks of therapy with infliximab. Forty-seven per cent of the infliximab-treated subjects attained an American College of Rheumatology (ACR) 20 response, while $53 \%$ did not. The baseline levels of TNF- $\alpha$, IL- $1 \alpha,-1 \beta$ did not differ between infliximab responders and infliximab-non-responders or in their ACR20 or ACR70 responses to infliximab. However, the immunoreactivity of TNF- $\alpha$ and IL- 6 was reduced in the synovial sublining layer as was sublining vascularity, but only in the infliximab responder group. There also was evidence for a reduction in membranous layer proliferation, but elevated numbers of $\mathrm{CD} 68^{+}$cells persisted. These results indicated that pre-infliximab synovial tissue immunoreactive TNF- $\alpha$ failed to predict infliximab responsiveness. However, in those RA patients who responded favorably to infliximab (with the exception of 'weak' responders), the response to 
infliximab mirrored a reduction in synovial tissue TNF- $\alpha$ and IL-6.

Sundberg et al ${ }^{101}$ recently showed that HMGB 1 expression $^{84,85}$ in RA synovial tissue was not consistently altered by infliximab therapy. Out of a total of 9 RA patients studied by pre- and post-infliximab synovial biopsy, the cytoplasmic and extracellular evidence of HMGB1 decreased in 5 patients, remained unchanged in 1 patient and was actually increased in 3 patients. Unfortunately, the variable changes that were detected in synovial tissue HMGB1 after infliximab therapy were not correlated with any measurements of TNF- $\alpha$, IL- $1 \beta$ or IL- 6 , or with IFN- $\gamma$, nitric oxide or TLRs, ${ }^{102}$ the last named having been identified as potential modifiers of HMGB1 expression, translocation and extracellular release.

Finally, Knudsen et al ${ }^{103}$ studied 20 RA patients with high baseline levels of plasma IL-6 and and VEGF and serum YKL-40, prior to infliximab plus methotrexate therapy. YKL-40 is produced by macrophages, synovial fibroblasts and chondrocytes and was recently shown to be elevated in patients with early RA. ${ }^{104}$ VEGF plays a prominent role in the neovascularization of synovial membrane in RA. ${ }^{56}$ Prior to therapy with infliximab, a strong correlation was obtained between elevated plasma IL-6, plasma VEGF and serum YKL-40. Moreover, a high baseline plasma IL-6 (ie, $>13 \mathrm{ng} / \mathrm{L}$; normal, $\leq 3.3$ ), even in those subjects who responded to therapy, predicted a greater progression of RA and higher Sharp scores after 52 weeks of therapy. The reduction in the level of plasma IL-6 was more strongly correlated with reduced ESR and CRP and the Disease Activity Score-28 (DAS-28) than when serum YKL-40 or plasma VEGF were correlated with ESR, CRP and DAS-28. Furthermore, the reduction in plasma IL-6 after therapy appears to be the principle biomarker of RA responsiveness to infliximab. However, changes in plasma IL-6 provided no better monitoring for infliximab responsiveness than a reduction in plasma CRP that also occurred after clinical responses to infliximab were obtained. ${ }^{104}$

\section{Etanercept}

Cordiali-Fei et al ${ }^{105}$ collected serum from 45 PsA patients prior to, and after therapy with etanercept for 52 weeks. A significant decline in the Psoriatic Arthritis Scoring Index (PSAI), and IL-1, IL-6 and INF- $\gamma$ was obtained (all $P<0.01$ ) and to a lesser extent in TNF- $\alpha(P<0.05)$. However, there were no significant changes in anti-nuclear antibody titer, $\mathrm{CD}^{+} / \mathrm{CD}^{+}$ratio, $\mathrm{IgE}, \mathrm{CD} 16$ (ie, $\mathrm{F}_{\mathrm{c}}$ receptors for $\mathrm{F}_{c \gamma} \mathrm{RIII}$ and $\mathrm{F}_{c \gamma} \mathrm{RIIIb}$ ), CD19 (ie, a plasma membrane marker for follicular dendritic cells and B-lymphocytes) or eosinophils.
CD45 is a cell surface marker for protein tyrosine phosphatase-mediated signal transduction through the T lymphocyte receptor which can induce T lymphocyte and B lymphocyte apoptosis. ${ }^{1}$ Tumor necrosis factor-related weak inducer of apoptosis (TWEAK) ${ }^{55}$ was detected on CD45 ${ }^{+}$ cells in RA synovium and cultured RA-FLS in the presence of TWEAK produced increased amounts of IL-6, IL-8 and MCP-1. ${ }^{106}$ Park et $\mathrm{al}^{107}$ showed that RA patients had higher serum TWEAK, TNF- $\alpha$ and IL- 6 levels than levels of these 3 biomarkers measured in a control group, whereas patients with AS had high levels of TNF- $\alpha$ and IL-6, but TWEAK levels were comparable to that of the control group. In RA, high TWEAK was correlated with a high DAS-28 score and high TNF- $\alpha$, but not with elevated IL-6. RA patients clinically responding to 12 weeks of therapy with etanercept also showed a reduction in serum TWEAK, whereas RA patients failing to respond to etanercept did not show any changes in serum TWEAK from baseline. However, an analysis to determine the extent to which a reduction in serum TWEAK correlated with changes in IL-6, TNF- $\alpha$ and IFN- $\gamma$ was not performed.

\section{Adalimumab}

Gene expression studies were conducted to attempt to predict the extent to which RA patients would respond to adalimumab. ${ }^{108}$ Four hundred-thirty-nine genes were identified which were associated with a poor clinical response to adalimumab using the criteria established by the European League Against Rheumatism. Four hundred eleven (94\%) of the 439 genes were upregulated in the poor responders to adalimumab group. These genes clustered into cell division or immune response pathways. Of interest, high baseline synovial gene expression of IL-7R, CXCL11, IL-18, IL-18 receptor accessory protein (IL-18rap) and MK167 were members of the gene panel that correlated with a poor clinical response to adalimumab. The high baseline expression of these molecules in RA patients prompted the possibility that TNF- $\alpha$, or other cytokines involved in RA pathophysiology including IL-6, might be responsible for the elevated IL-7R, CXCL11, IL-18, IL-18rap and MK167 gene expression by RA synovium. Thus, RA-FLS were incubated with TNF- $\alpha$, IL-1 $\beta$, IL-6, IL-7, IL-17 or various combinations thereof and real-time PCR was employed to determine the level of IL-7R, CXCL11, IL-18, IL-18rap and MK167 gene expression. TNF- $\alpha$, IL-1 $\beta$ or IL-17 alone produced results similar to the baseline values for some of the molecules in the aforementioned gene panel, whereas the combination of TNF- $\alpha$ or IL-1 $\beta$ with IL-17 produced a stimulatory effect 
on all of the genes in the gene panel. Of note, the effects of TNF- $\alpha$ with either IL-17 or IL- $1 \beta$ were synergistic for several targets: for TNF- $\alpha$ and IL-17; IL-6 and CDC2 (a serine/threonine kinase essential for cell division); and for TNF- $\alpha$ and IL-1 $\beta$; IL-7R, IL-6, indoleamine-pyrrole 2, 3, dioxygenase (an immunomodulatory enzyme) and CDC2. Future studies of this nature are warranted to determine if individualized biologic therapies can be designed to inhibit the expression of immunomodulatory genes that dampen clinical responses to RA biological drugs.

\section{Tocilizumab}

At present, tocilizumab is approved for use in the United States only for the treatment of JIA which has proven difficult to successfully manage by conventional therapies alone. ${ }^{109}$ The major safety and efficacy JIA clinical trial with tocilizumab had either a double-blinded placebo-controlled or open-labeled withdrawal design and was conducted in Japan on 52 children, ages 2 to 19 years, with disease who were refractory to conventional treatments. ${ }^{110}$ At the end of the open-label lead-in phase, the ACR Pedi 30, 50 and 70 responses were, $91 \%, 86 \%$ and $68 \%$, respectively. Seventeen per cent of JIA patients in the non-tocilizumabtreated group attained an ACR Pedi 30 response and a CRP concentration $<15 \mathrm{mg} / \mathrm{L}$ compared with $80 \%$ in the tocilizumab group. By week 48 of the open-label extension phase, the ACR Pedi 30, 50, 70 responses had risen to 98\%, 94\% and $90 \%$, respectively. These results are compelling in light of an older report by Peake et $\mathrm{al}^{111}$ who had cautioned that it might be difficult to see the effects of neutralizing IL-6 transsignaling in JIA because of the presence of high levels of proteolytically cleaved sIL-6R which might already interfere with IL-6-mediated trans-signaling in these patients.

Although serial measurement studies of serum IL-6 levels in JIA patients prior to, and after treatment with tocilizumab, are apparently forthcoming, Nakajima et $\mathrm{al}^{112}$ has already shown that the level of serum cartilage oligomeric matrix protein (COMP), a $550 \mathrm{kDa}$ homopentameric glycoprotein related to the thrombospondin protein family was increased by therapy with tocilizumab in systemic JIA (sJIA) patients after it was found that these patients were intolerant or had inadequate clinical responses to corticosteroids or immunosuppressants. The significance of raising serum COMP in sJIA may be related to the fact that serum COMP levels are generally below normal levels in sJIA during both active (ie, $\mathrm{CRP} \geq 1.5 \mathrm{mg} / \mathrm{dL}$ ) and remission stages $(\mathrm{CRP}<1.5 \mathrm{mg} / \mathrm{dL})$ of the disease. Low serum COMP may partially explain the limited progression of skeletal long bone growth in these patients. ${ }^{56}$ In this study ${ }^{112}$ the serum COMP level in 201 healthy children under the age of 16 years with no evidence of growth delay was $17.4 \pm 5.6 \mathrm{U} / \mathrm{L}$ (mean $\pm \mathrm{SD}$ ), in 11 sJIA patients, $10.8 \pm 3.9$, prior to tocilizumab and $14.9 \pm$ $3.9(P<0.05)$ after tocilizumab therapy for an indeterminate period of time, not stated in the report. The increase in serum COMP in the tocilizumab-treated group was accompanied by significant reductions in leukocyte count, ESR, CRP and ferritin which was also associated with a decrement in MMP-3 and a rise in bone alkaline phosphatase activity, the latter a well-validated biomarker of bone formation.

The results of 4 recently completed double-blind placebocontrolled randomized trials of tocilizumab in adult $\mathrm{RA}^{113-116}$ has also yielded impressive clinical results. Nishimoto et $\mathrm{al}^{113}$ conducted the first large clinical trial with tocilizumab on 302 subjects with active RA of $<5$ years duration but with very high modified Sharp scores at baseline, averaging 29.4. After 52 weeks of treatment, the tocilizumab-treated group $(8 \mathrm{mg} / \mathrm{kg})$ showed significantly less radiographic change (2.3, $95 \%$ CI, 1.5 to 3.2) compared to the DMARD-treated group $(6.1,95 \% \mathrm{CI}, 4.2$ to 8.0$)(P<0.01)$. A follow-up analysis also indicated a remission rate of $59 \%$ in the tocilizumab group as measured by DAS-28. Smolen et al ${ }^{114}$ reported that after 24 weeks, the ACR 20 response was 59\% in subjects receiving tocilizumab $(8 \mathrm{mg} / \mathrm{kg}), 48 \%$ in the group receiving $4 \mathrm{mg} / \mathrm{kg}$ and $26 \%$ in the placebo (ie, the methotrexate group). Sixty-nine per cent of the subjects receiving the higher dose of tocilizumab had at least 1 adverse event compared to $71 \%$ at the lower tocilizumab dose group and $63 \%$ in the placebo group. Emery et $\mathrm{al}^{115}$ reported a lower ACR20 and DAS-28 response to tocilizumab after 24 weeks compared to the results reported by Smolen et $\mathrm{al}^{114}$ but the response to tocilizumab was clearly in a positive direction; ACR20, 50\% (8 mg/kg), 30.4\% (4 mg/kg), 10.1\% (placebo); reduction in DAS-28, 30.1\% (8 mg/kg), 7.6\% (4 mg/kg), $1.6 \%$ (placebo). The results of this study ${ }^{115}$ also showed that subjects responded to tocilizumab regardless of whether they had recently failed to respond to one anti-TNF therapy or a number of anti-TNF regimens. Another follow-up study by Funahashi et al ${ }^{116}$ employed the clinical disease activity index (CDAI) in order to be able to compare the results using CDAI to DAS-28 to determine the responsiveness of RA subjects to tocilizumab for 12 weeks. This group also measured serum IL-6 and MMP-3 levels. Remission rates were reported as $57.1 \%$ using DAS-28 and $19.1 \%$ using CDAI, the latter being independent of blood data. However, CDAI correlated with DAS-28 and also with lowered serum values for MMP-3 and IL-6. Another marker 
of RA disease activity is the lowed secretion of biologically active adrenal androgens in relation to that of their precursor hormones and estrogens. Straub et $\mathrm{al}^{117}$ showed that the antiIL-6 antibody, MRA ( $8 \mathrm{mg} / \mathrm{kg}$ ) lowered the ESR, swollen joint counts and DAS- 28 but also increased the serum levels of androstenedione. The androstenedione to cortisol ratio increased in RA subjects receiving MRA compared to RA subjects receiving prednisolone or placebo. Importantly, serum levels of estrone and $17 \beta$-estradiol did not change, nor did serum levels of ACTH or cortisol.

\section{Potential use of novel inhibitors of IL-6 protein family members as RA therapeutics}

\section{APN and PBEF}

Anti-adipocytokine antibodies, including those directed against APN and PBEF are being evaluated for the treatment of RA. In a baseline analysis, Rho et a $1^{118}$ examined the level of serum leptin, resistin, APN and PBEF in 167 RA patients and 91 control subjects. An independent association analyses was conducted to determine the relationships between leptin, resistin, APN and PBEF and body mass index (BMI) as a measure of obesity and with serum CRP, IL- 6 and TNF- $\alpha$, as indices of inflammation. Radiographic damage was determined by Larsen scoring, which is also used to assess the radiographic progression of RA. The serum level of leptin, resistin, APN and PBEF were all elevated in the RA group compared to the control subjects. However, only APN and PBEF remained elevated after adjusting for BMI, the inflammation index or both. Moreover, PBEF was highly correlated with a high Larsen score, indicative of evidence of greater radiological joint damage. An association between PBEF and Larsen score remained high even after adjusting for age, race, sex, disease duration, BMI and the inflammation index. As expected, serum leptin was positively correlated with BMI, but leptin was negatively associated with Larsen scores after adjusting for inflammation, but not after adjusting for BMI. Not only will it be important to add the monitoring of serum APN and PBEF levels as a function of responsiveness of RA patients to anti-rheumatic biological agents, but these data also imply that the anti-APN/anti-PBEF biologicals may be suitable targets for future commercial drug development.

\section{OSM and leukemia inhibitory factor}

$\mathrm{OSM}^{119}$ and leukemia inhibitory factor (LIF), another member of the IL-6-like cytokine protein family, ${ }^{120}$ are appreciably elevated in RA serum and RA-SF. Experimental LIF antagonists are being evaluated in vitro in order to determine if they possess biological activity not only against LIF, but OSM as well, since LIF and OSM share an identical receptor which complexes with the gp130 subunit. ${ }^{1}$ In that regard, Jazayeri et al ${ }^{121}$ created two LIF mutants, LIF05 and MH35-BD, which have significantly reduced affinity for the gp130 subunit, but significant LIF receptor binding activity. The results showed that LIF mutations modulated the biological activity of LIF, OSM and other IL-6-like proteins as measured by reductions in $\mathrm{Ba} / \mathrm{F} 3$ cell proliferation, haptoglobin-induced HepG2 human carcinoma proliferation and proteoglycan and collagen release from porcine cartilage slices in vitro. More recently, MH35-BD was shown to block MMP-1, MMP-3 and TIMP-3 gene expression after stimulation of porcine chondrocytes with either LIF or OSM. ${ }^{122}$ Metz et al ${ }^{123}$ showed that a truncated form of the murine LIF receptor (LIF-R) made up of the first 5 extracellular domains was a potent inhibitor for human LIF. Thus, activation of Stat 3 and subsequent downstream induction of Stat 3 target genes were blocked by the truncated form of LIF-R. Furthermore, truncated LIF-R did not inhibit the biological activities of OSM or IL-6. The construction of LIF-based inhibitors by fusion protein methodology $y^{116}$ should enable the development of inhibitors for LIF-related cytokines, such as OSM as well as the newly recognized, IL-6-like cytokines, IL-31 and IL-27. ${ }^{28}$

\section{Does the anti-B-lymphocyte therapeutic agent, rituximab, alter IL-6 levels?}

The approval of the anti-CD20 antibody (ie, antimemory-B-lymphocyte), rituximab for use in the therapy of moderate-to-severe of RA patients with inadequate responses to anti-TNF- $\alpha$ biologicals ${ }^{25,124,125}$ has raised the possibility that rituximab could be employed to study other B-lymphocyte activities, including BAFF/APRIL and IL-6/ IL-6R/gp130-mediated signaling. Using biochip technology, Fabre et al ${ }^{126}$ studied cytokine responses in RA patients who demonstrated either a good or poor response to rituximab. Responder subjects were defined as meeting at least 3 of 4 ACR criteria: $\geq 20 \%$ fall in CRP, visual analog score of disease activity, ESR, and improvement in DAS-28 (4-values) or a reduction of $\geq 1.2$ in these values obtained after 3 months after rituximab therapy. The results showed that serum CRP and IL-6 levels were significantly decreased in the rituximabresponder group compared to baseline. However, high levels of MCP-1 and epidermal growth factor were the only 2 out of the 12 cytokines that distinguished rituximab-responders from non-responders. Furthermore, none of the baseline cytokine levels could predict clinical responses to rituximab. 


\section{Is IL-6 one of the biomarkers that are common to RA and OA?}

Although it is certain that the pathogenetic mechanisms causing RA and OA are different, there are specific components in RA and OA disease progression that suggested a common pathway in both diseases where destruction of articular cartilage and subchondral bone were the final outcome. ${ }^{127}$ A preliminary analysis of key regulatory molecules as measured by antibody-based protein membrane arrays that were associated with cartilage destruction, included IL-6, CCL2, CXCL1-3, IL-8/CXCL8, whereas a genome-wide microarray analysis of human chondrocytes stimulated by the SF from RA patients included adenosine A2A receptor, COX-2, TLR-2, spermine synthase, receptor-interacting serine-threonine kinase-2, CXCL1, CXCL8, CCL20, CXCR4, IL-1 $\beta$, IL-6, as well as MMP-10 (stromelysin-2) and MMP-12 (human macrophage elastase). ${ }^{129} \mathrm{~A}$ second study by Andreas et al ${ }^{129}$ identified additional novel genes that appeared to be part of the signature of inflamed synovium in RA, including connective tissue growth factor (CTGF), CXCR7, IL-23A, TNFAIP-2 and TXNIP, to name only a few. A similar analysis performed on inflamed synovium from $\mathrm{OA}$ patients could provide evidence for common gene expressional events that link RA to OA disease progression.

\section{A role emerges for IL-6 in OA, psoriatic arthritis and ankylosing spondylitis $\mathrm{OA}$}

The reasons for considering development of anti-IL-6 therapies for OA were recently reviewed. ${ }^{63}$ Perhaps the most compelling evidence linking IL-6 to OA pathogenesis came from cytokine profiling studies performed in the Hartley (OA-prone) and Strain-13 (OA-resistant) guinea pig. These studies were instrumental in focusing attention on the potential role of IL-6 in OA pathogenesis. Thus, multiple regression analysis showed significantly increased levels of serum IL-6 $\left(\mathrm{r}^{2}=0.80\right.$, $P=0.0002)$ and TNF- $\alpha\left(\mathrm{r}^{2}=0.55, P=0.02\right)$ in the OA-prone Hartley strain but not in Strain-13. ${ }^{130}$ An increase in the level of serum IL-6 and extracellular HMGB-1 were also found in the SF and osteochondral fragments of horses with OA. ${ }^{131}$

IL-6 in the presence of cyclic AMP (cAMP) was found to stimulate the production of cathepsin B in the MG-63 human osteoblast cell line. ${ }^{132}$ Stimulation of cathepsin B by IL- 6 and cAMP was dependent on p38 kinase activity. Moreover, IL-6 stimulated the production of urokinase-type plasminogen activator, a well-established activator of pro-MMPs. ${ }^{133}$ Of note, Straub et al ${ }^{134}$ recently showed that endomorphin-1
(EM-1), an anti-inflammatory molecule, inhibited IL-6 by RA synovial cells and IL-8 in RA and OA synovial cells. A similar pattern of inhibition by EM-1 was observed in the rat adjuvant arthritis model suggesting that stimulation of EM-1 might suppress IL-6 and/or IL-8 production by RA and $\mathrm{OA}$ inflamed synovium.

IL-6 may also be a critical modulator of chondrocyte differentiation from MSCs. Thus, IL-6 could play a significant negative role in cartilage regeneration in OA. In that regard, Nakajima et a ${ }^{135}$ showed that IL-6 inhibited early differentiation in the ATDC5 chondrogenic progenitor cell line which could be blocked by monoclonal antibody MR16-1. The blockade of IL-6 by MR16-1 resulted in the expression of IL-6R and gp 130 by ATDC 5 cells.

\section{PsA}

Infliximab and etanercept have achieved significant clinical efficacy in the treatment of psoriasis and PsA..$^{105,136-138}$ In that regard, the effective reduction in the clinical severity of psoriatic arthritis after 6 and 12 weeks of infliximab monotherapy was accompanied by reduced serum levels of IL-6, VEGF, E-selectin and FGF. ${ }^{139}$ In a more recent clinical trial ${ }^{140}$ a reduction in the serum and skin levels of MMP-2, MMP-9 and TNF- $\alpha$ was also obtained. Most recently, Alenius et a ${ }^{197}$ showed that serum IL-6 levels were higher in psoriatic patients with joint disease and measurable inflammation compared to patients with only the skin manifestations of psoriatic disease. Moreover, serum IL-6 and CRP levels strongly correlated with the actual inflamed joint count whereas the level of soluble IL-2R $\alpha$ did not. Taken together, the results of these clinical studies indicated that IL- 6 was one of the reliable serum biomarkers to measure during therapy of PsA with TNF- $\alpha$ inhibitors because IL- 6 is elevated in PsA and a reduction in IL-6 was achieved only when effective clinical remission was attained.

\section{AS}

Neutralizing antibodies against TNF- $\alpha$, IL-6 and IL-17 appear to be among the most promising approaches for reducing inflammation-mediated bone damage associated with AS. ${ }^{141}$ In this regard, Bal et al ${ }^{142}$ found increased serum levels of IL-6, sIL-2r and TNF- $\alpha$, but not IL- $1 \beta$ in AS patients with a correlation between CRP and IL- 6 as well as between ESR, sIL-2r, IL-6 and TNF- $\alpha$. However, only sIL-2R levels correlated with the Bath Ankylosing Spondylitis Metrology Index or the Bath Ankylosing Spondylitis Functional Index. Serum leptin levels and BMI were also found to correlate with IL-6 as did serum leptin levels and BMI and IL-6 with 
Table I Potential role of IL-6 cytokine protein family members in arthritis

\begin{tabular}{lllll}
\hline IL-6 family member & Increased in RA? & Reduced by anti-IL-6? & Reduced by inhibiting LIF-R? & References \\
\hline APN & Yes & $?$ & $?$ & 118 \\
OSM & Yes & $?$ & No & $119,123^{\mathrm{a}}$ \\
PBEF & Yes & $?$ & $?$ & 118 \\
LIF & Yes & $?$ & Yes & $120,123^{\mathrm{a}}$ \\
\hline
\end{tabular}

alnhibiting LIF-R did not alter the biological activity of IL-6.

Abbreviations: APN, adiponectin; OSM, oncostatin M; PBEF, pre-B-cell colony enhancing factor/visfatin; LIF, leukemia inhibitory factor.

the Bath Ankylosing Spondylitis Disease Activity Index and with serum CRP. ${ }^{143}$ Of note, a significant reduction in the level of serum IL-6, VEGF and CRP was achieved in patients with AS who were treated with infliximab for 2 and 24 weeks compared to placebo. The reduction in IL-6, VEGF and CRP was accompanied by a significant clinical response rate over the same period of time. ${ }^{144}$ Most recently, Visvanathan et $\mathrm{al}^{145}$ showed that an increase in spine bone mineral density in patients with AS after being treated with infliximab for 24 and 102 weeks correlated with baseline serum levels of IL-6, VEGF, osteocalcin, bone alkaline phosphatase and Type I collagen telopeptide. However, high baseline levels of osteocalcin and an early increase in the level of bone alkaline phosphatase were the most significant predictors of increased spine bone mineral density produced by infliximab in these patients.

\section{Conclusion}

Recent studies have implicated increased serum and SF levels of IL-6 and IL-6/IL-6R/gp130-mediated trans-signaling in a host of pathophysiologic events that characterize the inflammatory component of RA. Results of 4 clinical arthritis trials with anti-IL-6R antibodies for patients who had inadequate responses to corticosteroids, DMARDs or antiTNF-therapy provided compelling evidence that neutralizing IL-6-mediated signaling provided significant clinical benefit. However, several critical issues remain with regard to the extent to which other proteins members of the IL- 6 cytokine family, namely, APN, OSM and PBEF and LIF, will also inhibited by blockade of IL-6R (Table 1).

Recent evidence has also emerged linking the upregulation of IL- 6 gene expression to the development of OA in animals. However, it appears to be somewhat premature to commit any substantial financial resources to human OA clinical trials for which the safety and/or efficacy of neutralizing IL-6R would be determined.

Finally, since the soluble form of IL-6R acts as an agonist for the transmitting of signals through its interaction with gp130, ${ }^{145}$ it appears likely that novel approaches for employing and producing recombinant sgp130 protein to inhibit IL-6 trans-signaling will become part of the next generation for drug development of IL-6 pathway neutralizing agents.

\section{Addendum}

After the submission of this manuscript, Axmann et al ${ }^{147}$ showed that blockade of IL-6R with an experimental murine anti-IL-6R antibody directly reduced osteoclast differentiation and bone resorption by monocyte cultures stimulated with RANKL or RANKL plus TNF- $\alpha$ in vitro. In human TNF- $\alpha$ transgenic mice IL- 6 blockade did not inhibit joint inflammation, but did suppress osteoclast development and bone erosions. These results suggested that anti-IL-6 therapy directly reduced osteoclast-mediated bone destruction that was independent of its anti-inflammatory properties.

\section{Disclosure}

The author discloses no conflicts of interest.

\section{References}

1. Malemud CJ, Pearlman E. Targeting JAK/STAT signaling pathway in inflammatory diseases. Curr Signal Transduct Ther. 2009;4:201-221.

2. Christodoulou C, Choy EH. Joint inflammation and cytokine inhibition in rheumatoid arthritis. Clin Exp Med. 2006;6(1):13-19.

3. Rose-John S, Scheller J, Elson G, Jones SA. Interleukin-6 biology is coordinated by membrane-bound and soluble receptors: role in inflammation and cancer. J Leukoc Biol. 2006;80(2):227-236.

4. Kishimoto T. Interleukin-6: discovery of a pleiotropic cytokine. Arthritis Res Ther. 2006;8 Suppl 2:S2.

5. Nishimoto N, Kishimoto T. Interleukin-6: from bench to bedside. Nat Clin Pract Rheumatol. 2006;2(11):619-626.

6. Smolen JS, Maini RN. Interleukin-6: a new therapeutic target. Arthritis Res Ther. 2006;8 Suppl 2:S5.

7. Gabay C. Interleukin-6 and chronic inflammation. Arthritis Res Ther. 2006;8 Suppl 2:S3.

8. Lipsky PE. Interleukin-6 and rheumatic diseases. Arthritis Res Ther. 2006;8 Suppl 2:S4.

9. Paul-Pletzer K. Tocilizumab: blockade of interleukin-6 signaling pathway as a therapeutic strategy for inflammatory disorders. Drugs Today (Barc). 2006;42(9):559-576.

10. Crawford M, Moreland L. Interleukin-6 receptor antagonist as therapy for rheumatoid arthritis. Curr Rheumatol Rep. 2007;9(5):393-394. 
11. Nishimoto N, Kishimoto K. Humanized antihuman IL-6 antibody, tocilizumab. Handb Exp Pharmacol. 2008;(181):151-160.

12. Sebba A. Tocilizumab: the first interleukin-6 receptor inhibitor. $A m J$ Health Syst Pharm. 2008;65(15):1413-1418.

13. Oldfield V, Dhillon S, Plosker GL. Tocilizumab: a review of its use in the management of rheumatoid arthritis. Drugs. 2009;69(5):609-632

14. Kinjyo I, Ohishi M, Shouda T, Kobayashi T, Yoshimura A. Positive and negative roles of IL-6, STAT3, and SOCS3 in inflammatory arthritis. Adv Exp Med Biol. 2007;602:113-124.

15. Naugler WE, Karin M. The wolf in sheep's clothing: the role of interleukin-6 in immunity, inflammation and cancer. Trends Mol Med. 2008;14(3):109-119.

16. Fonseca JE, Santos MJ, Canhão H, Choy E. Interleukin-6 as a key player in systemic inflammation and joint destruction. Autoimmun Rev. 2009;8(7):538-542.

17. Rose-John S, Waetzig GH, Scheller J, Grötzinger J, Seegert D. The IL-6/sIL-6R complex as a novel target for therapeutic approaches. Expert Opin Ther Targets. 2007;11(5):613-624.

18. Finckh A, Gabay C. At the horizon of innovative therapy in rheumatology: new biologic agents. Curr Opin Rheumatol. 2008;20(3):269-275.

19. Schett G. Review: immune cells and mediators in inflammatory arthritis. Autoimmunity. 2008;41(3):224-229.

20. Brennan FM, McInnes IB. Evidence that cytokines play a role in rheumatoid arthritis. J Clin Invest. 2008;118(11):3537-3545.

21. Choy E. Inhibiting interleukin-6 in rheumatoid arthritis. Curr Rheumatol Rep. 2008;10(5):413-417.

22. Raj DS. Role of interleukin-6 in the anemia of chronic disease. Semin Arthritis Rheum. 2009;38(5):382-388.

23. Mima T, Nishimoto N. Clinical value of blocking IL-6 receptor. Curr Opin Rheumatol. 2009;21(3):224-230.

24. De Benedetti F. Targeting interleukin-6 in pediatric rheumatic diseases. Curr Opin Rheumatol. 2009;21(5):533-537.

25. Youinou P, Jamin C. The weight of interleukin-6 in B cell-related autoimmune disorders. Autoimmun. 2009;32(3-4):206-210.

26. de Pablo P, Chapple IL, Buckley CD, Dietrich T. Periodontitis in systemic rheumatic diseases. Nat Rev Rheumatol. 2009;5(4):218-224.

27. Takatori H, Kanno Y, Chen Z, O'Shea JJ. New complexities in helper $T$ cell fate determination and the implications for autoimmune diseases. Mod Rheumatol. 2008;18(6):533-541.

28. Malemud CJ, Reddy SK. Targeting cytokines, chemokines and adhesion molecules in rheumatoid arthritis. Curr Rheum Rev. 2008;4:219-234.

29. Bettelli E, Korn T, Kuchroo VK. Th17; the third member of the effector T cell trilogy. Curr Opin Immunol. 2007;19(6):652-657.

30. Layh-Schmitt G, Colbert RA. The interleukin-23/interleukin-17 axis in spondyloarthritis. Curr Opin Rheumatol. 2008;20(4):392-397.

31. Chen Z, O'Shea JJ. Th17 cells: a new fate for differentiating helper T cells. Immunol Res. 2008;41(2):87-102.

32. Korn T, Bettelli E, Oukka M, Kuchroo VK. IL-17 and Th17 cells. Annu Rev Immunol. 2009;27:485-517.

33. Mihara M, Ohsugi Y, Kishimoto T. Evidence for the role of Th17 cell inhibition in the prevention of autoimmune diseases by anti-interleukin- 6 receptor antibody. Biofactors. 2009;35(1):47-51.

34. Ogura H, Murakami M, Okuyama Y, et al. Interleukin-17 promotes autoimmunity by triggering a positive-feedback loop via interleukin-6 production. Immunity. 2008;29(4):628-636.

35. Nishihara M, Ogura H, Ueda N, et al. IL-6-gp130-STAT3 in T cells directs the development of IL-17 $7^{+}$Th with a minimum effect on that of $\mathrm{T}_{\text {reg }}$ in the steady state. Int Immunol. 2007;19(6):695-702.

36. Maitra U, Davis S, Reilly CM, Li L. Differential regulation of FoxP3 and IL-17 expression in CD4 T helper cells by IRAK-1. J Immunol. 2009;182(9):5763-5769.

37. Fujimoto M, Serada S, Mihara M, et al. Interleukin-6 blockade suppresses autoimmune arthritis in mice by the inhibition of inflammatory Th17 responses. Arthritis Rheum. 2008;58(12):3710-3719.

38. Lee JH, Cho ML, Kim JI, et al. Interleukin-17 (IL-17) increases the expression of Toll-like receptor-2, 4 , and 9 by increasing IL- $1 \beta$ and IL- 6 production in autoimmune mice. $J$ Rheumatol. 2009;36(4):684-692.
39. Ospelt C, Brentano F, Rengel Y, et al. Overexpression of toll-like receptor 3 and 4 in synovial tissue from patients with early rheumatoid arthritis. Toll-like receptor expression in early and longstanding arthritis. Arthritis Rheum. 2008;58(12):3684-3692.

40. Palmer CD, Mutch BE, Workman S, McDaid JP, Horwood NJ, Foxwell BM. Bmx tyrosine kinase regulates TLR4-induced IL-6 production in human macrophages independently of p38 MAPK and NF- $\mathrm{KB}$ activity. Blood. 2008;111(4):1781-1788.

41. Malemud CJ. Role of non-receptor tyrosine and threonine kinase inhibitors. In: García-Foncillas J, editor. Molecular Biology of Cancer: Toward New Therapies. Barcelona: Prous Science SA. 2009:537-555

42. Palmer CD, Mutch BE, Page TH, Horwood NJ, Foxwell BM. Bmx regulates LPS-induced IL-6 and VEGF production via mRNA stability in rheumatoid synovial fibroblasts. Biochem Biophys Res Commun. 2008;370(4):599-602.

43. Hashizume M, Hayakawa N, Mihara M. IL-6 trans-signalling directly induces RANKL on fibroblast-like synovial cells and is involved in RANKL induction by TNF- $\alpha$ and IL-17. Rheumatology (Oxford). 2008;47(11):1635-1640.

44. Inoue T, Hammaker D, Boyle DL, Firestein GS. Regulation of p38 MAPK by MAPK kinases 3 and 6 in fibroblast-like synoviocytes. J Immunol. 2005;174(7):4301-4306.

45. Malemud CJ. Inhibitors of stress-activated/mitogen-activated protein kinase pathways. Curr Opin Pharmacol. 2007;7(3):339-343.

46. Malemud CJ. MAP kinases. In: Buckwalter J, Lotz M, Stoltz JF, editors. Osteoarthritis, Inflammation and Degradation: A Continuum. Amsterdam; IOS Press; 2007:99-117.

47. Inoue T, Boyle DL, Corr M, et al. Mitogen-activated protein kinase 3 is a pivotal pathway regulating $\mathrm{p} 38$ activation in inflammatory arthritis. Proc Natl Acad Sci U SA. 2006;103(14):5484-5489.

48. Yoshikawa T, Hammaker D, Boyle DL, et al. Role of MAPK kinase 6 in arthritis; distinct mechanism of action in inflammation and cytokine expression. J Immunol. 2009;183(2):1360-1367.

49. Singh R, Ahmed S, Malemud CJ, Goldberg VM, Haqqi TM. Epigallocatechin-3-gallate selectively inhibits interleukin-1 $\beta$-induced activation of mitogen activated protein kinase subgroup c-Jun $\mathrm{N}$-terminal kinase in human osteoarthritis chondrocytes. J Orthop Res. 2003;21(1):102-109.

50. Singh R, Ahmed S, Islam N, Goldberg VM, Haqqi TM. Epigallocatechin-3-gallate inhibits interleukin-1 $\beta$-induced expression of nitric oxide synthase and production of nitric oxide in human chondrocytes. Suppression of nuclear factor $\mathrm{\kappa B}$ activation by degradation of the inhibitor of nuclear factor KB. Arthritis Rheum. 2002;46(8):2079-2086.

51. Ahmed S, Marotte H, Kwan K, et al. Epigallocatechin-3-gallate inhibits IL-6 synthesis and suppresses transsignaling by enhancing soluble gp130 production. Proc Natl Acad Sci U S A. 2008;105(38):14692-14697.

52. Lee CH, Shieh DC, Tzeng CY, et al. Bradykinin-induced IL-6 expression through bradykinin $\mathrm{B} 2$ receptor, phospholipase $\mathrm{C}$, protein kinase $\mathrm{C} \delta$ and NF- $\mathrm{kB}$ pathway in human synovial fibroblasts. Mol Immunol. 2008;45(14):3693-3702.

53. Anderson KC. Proteasome inhibitors in multiple myeloma. Semin Oncol. 2009;36(2 Suppl):S20-S26.

54. Lee SW, Kim JH, Park YB, Lee SK. Bortezomib attenuates murine collagen-induced arthritis. Ann Rheum Dis. 2008. [Epub ahead of print]. PMID: 19054826.

55. Malemud CJ, Gillespie HJ. The role of apoptosis in arthritis. Curr Rheum Rev. 2005;1:131-142.

56. Malemud CJ. Growth hormone, VEGF and FGF; Involvement in rheumatoid arthritis. Clin Chim Acta. 2007;375(1-2):10-19.

57. Rochas C, Hillion S, Youinou P, Jamin C, Devauchelle-Pensec V. RAG-mediated secondary rearrangements of B-cell antigen receptors in rheumatoid synovial tissue. Autoimmun Rev. 2007;7(2):155-159.

58. Rochas C, Hillion S, Saraux A, et al. Transmembrane BAFF from rheumatoid synoviocytes requires interleukin-6 to induce the expression of recombination-activating gene in B lymphocytes. Arthritis Rheum. 2009;60(5):1261-1271. 
59. Mackay F, Sierro F, Grey ST, Gordon TP. The BAFF/APRIL system; an important player in systemic rheumatic diseases. Curr Dir Autoimmun. $2005 ; 8: 243-265$.

60. Ng LG, Mackay CR, Mackay F. The BAFF/APRIL system: life beyond B lymphocytes. Mol Immunol. 2005;42(7):763-772.

61. Ng LG, Ng CH, Woehl B, et al. BAFF costimulation of Toll-like receptor-activated B-1 cells. Eur J Immunol. 2006;36(7):1837-1846.

62. Vugmeyster Y, Seshasayee D, Chang W, et al. A soluble BAFF antagonist, BR3-Fc, decreases peripheral blood B cells and lymphoid tissue marginal zone and follicular B cells in cynomolgus monkeys. Am J Pathol. 2006;168(2):476-489.

63. Lai Kwan Lam Q, King Hung Ko O, Zheng BJ, Lu L. Local BAFF gene silencing suppresses $\mathrm{Th}_{17}$-cell generation and ameliorates autoimmune arthritis. Proc Natl Acad Sci U S A. 2009;105(39):14993-14998.

64. Daridon C, Burmester GR, Dörner T. Anticytokine therapy impacting on B cells in autoimmune diseases. Curr Opin Rheumatol. 2009;21(3):205-210.

65. Ehling A, Schäffler A, Herfarth $\mathrm{H}$, et al. The potential of adiponectin in driving arthritis. $J$ Immunol. 2006;176(7):4468-4478.

66. Haugen F, Drevon CA. Activation of nuclear factor- $\mathrm{\kappa B}$ by high molecular weight and globular adiponectin. Endocrinology. 2007;148(11): $5478-5486$

67. Tang CH, Chiu YC, Tan TW, Yang RS, Fu WM. Adiponectin enhances IL-6 production in human synovial fibroblast via an AdipoR1 receptor, AMPK, p38 and NF-אB pathway. J Immunol. 2007;179(8): $5483-5492$

68. Lee SW, Kim JH, Park MC, Park YB, Lee SK. Adiponectin mitigates the severity of arthritis in mice with collagen-induced arthritis. Scand J Rheumatol. 2008;37(4):260-268.

69. Malemud CJ. Anticytokine therapy for osteoarthritis; Evidence to date. Drugs Aging. (In press) 2009.

70. Hams E, Colmont CS, Dioszeghy V, et al. Oncostatin M receptor- $\beta$ signaling limits monocyte cell recruitment in acute inflammation. J Immunol. 2008;181(3):2174-2180.

71. Luk T, Malam Z, Marshall JC. Pre-B cell colony-enhancing factor (PBEF)/visfatin; a novel mediator of innate immunity. J Leukoc Biol. 2008;84(4):804-816.

72. Nowell MA, Richards PJ, Fielding CA, et al. Regulation of pre-B cell colony enhancing factor by STAT-3-dependent interleukin-6 trans-signaling. Implications in the pathogenesis of rheumatoid arthritis. Arthritis Rheum. 2006;54(7):2084-2095.

73. Brantano F, Schorr O, Ospelt C, et al. Pre-B cell colony enhancing factor/visfatin, a new marker of inflammation in rheumatoid arthritis with pro-inflammatory and matrix-degrading activities. Arthritis Rheum. 2007;56(9):2829-2839.

74. Nakamura T. Clinical strategies for amyloid A amyloidosis secondary to rheumatoid arthritis. Mod Rheumatol. 2008;18(2):109-118.

75. Koga $\mathrm{T}$, Torigoshi $\mathrm{T}$, Motokawa $\mathrm{S}$, et al. Serum amyloid A-induced IL-6 production by rheumatoid synoviocytes. FEBS Lett. 2008;582(5):579-585

76. Uchiyama Y, Yorozu K, Hashizume M, Moriya Y, Mihara M. Tocilizumab, a humanized anti-interleukin- 6 receptor antibody, ameliorates joint swelling in established monkey collagen-induced arthritis. Biol Pharm Bull. 2008;31(6):1159-1163.

77. Kato A, Matsuo S, Takai H, Uchiyama Y, Mihara M, Suzuki M. Early effects of tocilizumab on bone and bone marrow lesions in a collageninduced arthritis monkey model. Exp Mol Pathol. 2008;84(3):262-270.

78. Bockermann R, Schubert D, Kamradt T, Holmdahl R. Induction of a B-cell-dependent chronic arthritis with glucose-6-phosphate isomerase. Arthritis Res Ther. 2005;7(6):R1316-R1324.

79. Matsumoto I, Zhang H, Yasukochi T, et al. Therapeutic effects of antibodies to tumor necrosis factor- $\alpha$, interleukin- 6 and cytotoxic T-lymphocyte antigen 4 immunoglobulin in mice with glucose-6-phosphate isomerase induced arthritis. Arthritis Res Ther. 2008;10(3):R66.

80. Iwanami K, Matsumoto T, Tanaka-Watanabe Y, et al. Crucial role of the interleukin-6/interleukin-17 cytokine axis in the induction of arthritis by glucose-6-phosphate isomerase. Arthritis Rheum. 2008;58(3):754-763.
81. Wang JX, Tang W, Zhou R, et al. The new water-soluble artemisinin derivative SM905 ameliorates collagen-induced arthritis by suppression of inflammatory and Th17 responses. Br J Pharmacol. 2008; 153(6):1303-1310.

82. Suzuki M, Hashizume M, Yoshida H, Mihara M. Anti-inflammatory mechanism of tocilizumab, a humanized anti-IL-6R antibody; effect on the expression of chemokine and adhesion molecules. Rheumatol Int. 2009. [Epub ahead of print]. PMID:19466425.

83. Wong PKK, Quinn JM, Sims NA, van Nieuwenhuijze A, Campbell IK, Wicks JP. Interleukin-6 modulates production of T-lymphocyte-derived cytokines in antigen-induced arthritis and drives inflammation-induced osteoclastogenesis. Arthritis Rheum. 2006;54(1):158-168.

84. Lotze MT, Tracey KJ. High-mobility group box 1 protein (HMGB1); nuclear weapon in the immune arsenal. Nat Rev Immunol. 2005; 5(4):331-342.

85. Park JS, Gamboni-Robertson F, He Q, et al. High mobility group box 1 protein interacts with multiple Toll-like receptors. Am J Physiol Cell Physiol. 2006;290(3):C917-C924.

86. Orlova VV, Choi EY, Xie C, et al. A novel pathway of HMGB1mediated inflammatory cell recruitment that requires Mac-1 integrin. EMBO J. 2007;26(4):1129-1139.

87. Pullerits R, Jonsson IM, Kollias G, Tarkowski A. Induction of arthritis by high mobility group box chromosomal protein 1 is independent of tumour necrosis factor signalling. Arthritis Res Ther. 2008;10(3):R72.

88. Milici AJ, Kudlacz EM, Audoly L, Zwillich S, Changelian P. Cartilage preservation by inhibition of Janus kinase 3 in two rodent models of rheumatoid arthritis. Arthritis Res Ther. 2008;19(1):R14.

89. Tsuji F, Yoshimi M, Katsuta O, Takai M, Ishihara K, Aono H. Point mutation of tyrosine 759 of the IL- 6 family cytokine receptor, gp130, augments collagen-induced arthritis in DBA/1J mice. $B M C$ Musculoskelet Disord. 2009;10:23.

90. Sawa S, Kamimura D, Jin GH, et al. Autoimmune arthritis associated with mutated interleukin (IL)-6 receptor gp130 is driven by STAT3/ IL-7 dependent homeostatic proliferation of $\mathrm{CD}^{+}$cells. $J$ Exp Med. 2006;203(6):1459-1470.

91. Galle P, Jensen L, Andersson C, et al. Vaccination with IL-6 analogues induces autoantibodies to IL- 6 and influences experimentally-induced inflammation. Int Immunopharmacol. 2007;7(13):1704-1713.

92. Perry MG, Richards L, Harbuz MS, Jessop DS, Kirwan JR. Sequential synovial fluid sampling suggests plasma and synovial fluid IL-6 vary independently in rheumatoid arthritis. Rheumatology (Oxford). 2006;45(2):229-230.

93. Perry MG, Kirwan JR, Jessop DS, Hunt LP. Overnight variations in cortisol, interleukin 6, tumour necrosis factor $\alpha$ and other cytokines in people with rheumatoid arthritis. Ann Rheum Dis. 2009;68(1):63-68.

94. Matsumoto T, Tsurumoto T, Shindo H. Interleukin-6 levels in synovial fluids of patients with rheumatoid arthritis correlated with the infiltration of inflammatory cells in synovial membrane. Rheumatol Int. 2006;26(12):1096-1100.

95. Karlson EW, Chibnik LB, Tworoger SS, et al. Biomarkers of inflammation and development of rheumatoid arthritis in women from two prospective cohort studies. Arthritis Rheum. 2009;60(3):641-652.

96. de Jager W, Hoppenreijs EP, Wulffraat NM, Wedderburn LR, Kuis W, Prakken BJ. Blood and synovial fluid cytokine signatures in patients with juvenile idiopathic arthritis; a cross-sectional study. Ann Rheum Dis. 2007;66(5):589-598.

97. Alenius GM, Eriksson C, Rantapää Dahlqvist S. Interleukin-6 and soluble interleukin-2-receptor $\alpha$-markers of inflammation in patients with psoriatic arthritis? Clin Exp Rheumatol. 2009;27(1):120-123.

98. Sørensen LK, Havemose-Poulsen A, Bendtzen K, Holmstrup P. Aggressive periodontitis and chronic arthritis; blood mononuclear cell gene expression and plasma protein levels of cytokines and cytokine inhibitors. J Periodontol. 2009;80(2):282-289.

99. Amital H, Barak V, Winkler RE, Rubinow A. Impact of treatment with infliximab on serum cytokine profile of patients with rheumatoid and psoriatic arthritis. Ann NY Acad Sci. 2007;1110:649-660. 
100. Buch MH, Reece RJ, Quinn MA, et al. The value of synovial cytokine expression in predicting the clinical response to TNF antagonist therapy (infliximab). Rheumatology (Oxford). 2008;47(10): 1469-1475.

101. Sundberg E, Grundtman C, Af Klint E, et al. Systemic TNF blockade does not modulate synovial expression of pro-inflammatory mediator HMGB1 in rheumatoid arthritis patients - a prospective clinical study. Arthritis Res Ther. 2008;10(2):R33.

102. Harris HE, Raucci A. Alarmin(g) news about danger; workshop on innate danger signals and HMGB1. EMBO Rep. 2006;7(8):774-778.

103. Knudsen LS, Ostergaard M, Baslund B, et al. Plasma IL-6, plasma VEGF and serum YKL-40; relationship with disease activity and radiographic progression in rheumatoid arthritis patients treated with infliximab and methotrexate. Scand J Rheumatol. 2006;35(6):489-491.

104. Knudsen LS, Klarlund M, Skjødt H, et al. Biomarkers of inflammation in patients with unclassified polyarthritis and early rheumatoid arthritis. Relationship to disease activity and radiographic outcome. J Rheumatol. 2008;35(7):1277-1287.

105. Cordiali-Fei P, Ardigò M, Mastroianni A, et al. Serum cytokine and bioumoral immunological characterization of psoriatic patients in long term etanercept treatment. Int J Immunopathol Pharmacol. 2008;21(3):643-649.

106. Kamijo S, Nakajima A, Kamata K, Kurosawa H, Yagita H, Okumura K Involvement of TWEAK/Fn14 interaction in the synovial inflammation of RA. Rheumatology (Oxford). 2008;47(4):442-450.

107. Park MC, Chung SJ, Park YB, Lee SK. Relationship of serum TWEAK level to cytokine level, disease activity, and response to anti-TNF treatment in patients with rheumatoid arthritis. Scand J Rheumatol 2008;37(3):173-178.

108. Badot V, Galant C, Nzeusseu Toukap A, et al. Gene expression profiling in the synovium identifies predictive signature of absence of response to adalimumab therapy in rheumatoid arthritis. Arthritis Res Ther. 2009;11(2):R57.

109. Bongartz T. Tocilizumab for rheumatoid and juvenile idiopathic arthritis. Lancet. 2008;371(9617):961-963.

110. Yokota S, Imagawa T, Mori M, et al. Efficacy and safety of tocilizumab in patients with systemic-onset juvenile idiopathic arthritis: a randomised, double-blind, placebo-controlled, withdrawal phase III trial. Lancet. 2008;371(9617):998-1006.

111. Peake NJ, Khawaja K, Myers A, et al. Interleukin-6-signalling in juvenile idiopathic arthritis is limited by proteolytically cleaved soluble interleukin-6 receptor. Rheumatology (Oxford). 2006;45(12): 1485-1489.

112. Nakajima S, Naruto T, Miyamae T, et al. Improvement of reduced serum cartilage oligomeric matrix protein levels in systemic juvenile idiopathic arthritis patients treated with the anti-interleukin6-receptor monoclonal antibody tocilizumab. Mod Rheumatol. 2009;19(1):42-46.

113. Nishimoto N, Hashimoto J, Miyasaka N, et al. Study of active controlled monotherapy used for rheumatoid arthritis, an IL-6 inhibitor (SAMURAI); evidence of clinical and radiographic benefit from an X-ray reader-blinded randomised controlled trial of tocilizumab. Ann Rheum Dis. 2007;66(9):1162-1167.

114. Smolen JS, Beaulieu A, Rubbert-Roth A, et al. Effect of interleukin-6 receptor inhibition with tocilizumab in patients with rheumatoid arthritis (OPTION study); a double-blind, placebo-controlled, randomised trial. Lancet. 2008;371(9617):987-997.

115. Emery P, Keystone E, Tony HP, et al. IL-6 receptor inhibition with tocilizumab improves treatment outcomes in patients with rheumatoid arthritis refractory to anti-tumour factor biologicals; results from a 24-week multicentre randomised placebo-controlled trial. Ann Rheum Dis. 2008;67(11):1516-1523.

116. Funahashi K, Koyano S, Miura T, Hagiwara F, Okuda K, Matsubara T. Efficacy of tocilizumab and evaluation of clinical remission as determined by CDAI and MMP-3 levels. Mod Rheumatol. 2009. [Epub ahead of print]. PMID:19609487.
117. Straub RH, Härle P, Yamana S, et al. Anti-interleukin-6 receptor antibody therapy favors adrenal androgen secretion in patients with rheumatoid arthritis. A randomized, double-blind, placebo-controlled trial. Arthritis Rheum. 2006;54(6):1778-1785.

118. Rho YH, Solus J, Sokka T, et al. Adipocytokines are associated with radiographic joint damage in rheumatoid arthritis. Arthritis Rheum. 2009;60(7):1906-1914.

119. Barnes TC, Moots RJ. Targeting oncostatin M in the treatment of rheumatoid arthritis. In: Tak PP, editor. Progress in Inflammation Research. New Therapeutic Targets in Rheumatoid Arthritis. Basel, Birkhäuser. 2009:181-191.

120. Enomoto H, Saito S, Yabe H, Toyama Y, Tomatu T. The levels of leukemia inhibitory factor in synovial tissue of patients with rheumatoid arthritis; inflammation and other proinflammatory cytokines. Mod Rheumatol. 2003;13(2):121-128.

121. Jazayeri JA, De Weerd N, Raye W, Kivivuori S, Zabihi E, Carroll GJ. In vitro evaluation of leukemia inhibitory factor receptor antagonists as candidate therapeutics for inflammatory arthritis. J Interferon Cytokine Res. 2007;27(4):281-289.

122. Upadhyay A, Sharma G, Kivivuori S, et al. Role of LIF antagonist in LIF and OSM induced MMP-1, MMP-3, and TIMP-1 expression by primary articular chondrocytes. Cytokine. 2009;46(3):332-338.

123. Metz S, Naeth G, Heinrich PC, Müller-Newen G. Novel inhibitors for murine and human leukemia inhibitory factor based on fused soluble receptors. J Biol Chem. 2008;283(10):5985-5995.

124. Levesque MC, St. Clair EW. B-cell-directed therapies for autoimmune diseases and correlates of disease response and relapse. J Allergy Clin Immunol. 2008;121(1):13-21.

125. Dörner T, Radbruch A, Burmester GR. B-cell-directed therapies for autoimmune diseases. Nat Rev Rheumatol. 2009;5(8):433-441.

126. Fabre S, Guisset C, Tatem L, et al. Protein biochip array technology to monitor rituximab in rheumatoid arthritis. Clin Exp Immunol. 2009;155(3):395-402.

127. Malemud CJ, Schulte ME. Is there a final common pathway for arthritis? Fut Rheumatol. 2008;3:253-268.

128. Andreas K, Lübke C, Häupl T, et al. Key regulatory molecules of cartilage destruction in rheumatoid arthritis: an in vitro study. Arthritis Res Ther. 2008;10(1):R9.

129. Andreas K, Häupl T, Lübke C, et al. Antirheumatic drug response signatures in human chondrocytes; potential molecular targets to stimulate cartilage regeneration. Arthritis Res Ther. 2009;11(1):R15.

130. Huebner JL, Kraus VB. Assessment of the utility of biomarkers of osteoarthritis in the guinea pig. Osteoarthritis Cartilage. 2006;14(9):923-930.

131. Ley C, Ekman S, Ronéus B, Eloranta ML. Interleukin-6 and high mobility group box protein-1 in synovial membranes and osteochondral fragments in equine osteoarthritis. Res Vet Sci. 2009;86(3):490-497.

132. Chae HJ, Ha KC, Lee GY, et al. Interleukin-6 and cyclic AMP stimulate release of cathepsin B in human osteoblasts. Immunopharmacol Immunotoxicol. 2007;29(2):155-172.

133. Burrage PS, Mix KS, Brinckerhoff CE. Matrix metalloproteinases; role in arthritis. Front Biosci. 2006;11:529-543.

134. Straub RH, Wolff C, Fassoid A, et al. Antiinflammatory role of endomorphins in osteoarthritis, rheumatoid arthritis, and adjuvant-induced polyarthritis. Arthritis Rheum. 2008;58(2):456-466.

135. Nakajima S, Naruto T, Miyamae T, et al. Interleukin-6 inhibits early differentiation of ATDC5 chondrogenic progenitor cells. Cytokine. 2009;47(2):91-97.

136. Tobin AM, Kirby B. TNF $\alpha$ inhibitors in the treatment of psoriasis and psoriatic arthritis. Biodrugs. 2005;19(1):47-57.

137. Strober B, Teller C, Yamauchi P, et al. Effects of etanercept on C-reactive protein levels in psoriasis and psoriatic arthritis. $\mathrm{BrJ}$ Dermatol. 2008;159(2):322-330.

138. Villa-Forte A. Anticytokine therapy in non-rheumatoid arthritis indications in 2009. Curr Opin Rheumatol. 2009;21(3):251-255.

139. Mastroianni A, Minutilli E, Mussi A, et al. Cytokine profiles during infliximab monotherapy in psoriatic arthritis. Br J Dermatol. 2005; 153(3):531-536. 
140. Cordiali-Fei P, Trento E, D'Agosto G, et al. Effective therapy with anti-TNF- $\alpha$ in patients with psoriatic arthritis is associated with decreased levels of metalloproteinases and angiogenic cytokines in the sera and skin lesions. Ann NY Acad Sci. 2007;1110:578-589.

141. Herman S, Krönke G, Schett G. Molecular mechanisms of inflammatory bone damage; emerging targets for therapy. Trends Mol Med. 2008;14(6):245-253.

142. Bal A, Uniu E, Bahar G, Aydog E, Eksioglu E, Yorgancioglu R. Comparison of IL-1 $\beta$, sIL-2R, IL-6, and TNF- $\alpha$ levels with disease activity parameters in ankylosing spondylitis. Clin Rheumatol. 2007;26(2):211-215.

143. Park MC, Lee SW, Choi ST, Park YB, Lee SK. Serum leptin levels correlate with interleukin-6 levels and disease activity in patients with ankylosing spondylitis. Scand J Rheumatol. 2007;36(2):101-106.
144. Visvanathan S, Wagner C, Marini JC, et al. Inflammatory biomarkers, disease activity and spinal disease measures in patients with ankylosing spondylitis after treatment with infliximab. Ann Rheum Dis. 2008;67(4):511-517.

145. Visvanathan S, van der Heijde D, Deodhar A, et al. Effects of infliximab on markers of inflammation and bone turnover and associations with bone mineral density in patients with ankylosing spondylitis. Ann Rheum Dis. 2009;68(2):175-182.

146. Scheller J, Ohnesorge N, Rose-John S. Interleukin-6 trans-signaling in chronic inflammation and cancer. Scand J Immunol. 2006;63(5): 321-329.

147. Axmann R, Böhm C, Krönke G, Zwerina J, Smolen J, Schett G. Inhibition of interleukin-6 receptor directly blocks osteoclast formation in vitro and in vivo. Arthritis Rheum. 2009;60(9):2747-2756.

\section{Publish your work in this journal}

Open Access Rheumatology: Research and Reviews is an international, peer-reviewed, open access journal, publishing all aspects of clinical and experimental rheumatology in the clinic and laboratory including the following topics: Pathology, pathophysiology of rheumatological diseases; Investigation, treatment and management of rheumatological diseases; Clinical trials and novel pharmacological approaches for the treatment of rheumatological disorders. The manuscript management system is completely online and includes a very quick and fair peerreview system, which is all easy to use. Visit http://www.dovepress.com/ testimonials.php to read real quotes from published authors. 